This item was submitted to Loughborough's Research Repository by the author.

Items in Figshare are protected by copyright, with all rights reserved, unless otherwise indicated.

\title{
A deterministic approach for assessing tsunami-induced building damage through quantification of hydrodynamic forces
}

PLEASE CITE THE PUBLISHED VERSION

https://doi.org/10.1016/j.coastaleng.2018.11.002

PUBLISHER

(C) Elsevier

VERSION

AM (Accepted Manuscript)

\section{PUBLISHER STATEMENT}

This paper was accepted for publication in the journal Coastal Engineering and the definitive published version is available at https://doi.org/10.1016/j.coastaleng.2018.11.002.

\section{LICENCE}

CC BY-NC-ND 4.0

\section{REPOSITORY RECORD}

Xiong, Yan, Qiuhua Liang, Hyoungsu Park, Daniel Cox, and Gang Wang. 2019. "A Deterministic Approach for Assessing Tsunami-induced Building Damage Through Quantification of Hydrodynamic Forces”. figshare. https://hdl.handle.net/2134/36575. 


\title{
A Deterministic Approach for Assessing Tsunami-Induced Building Damage through Quantification of Hydrodynamic Forces
}

\author{
Yan Xiong ${ }^{1}$; Qiuhua Liang ${ }^{1,2^{*}}$; Hyoungsu Park $^{3}$; Daniel Cox ${ }^{3}$; Gang Wang ${ }^{1}$ \\ ${ }^{1}$ State Key Laboratory of Hydrology-Water Resources and Hydraulic Engineering, Hohai \\ University, Nanjing, 210098, China \\ ${ }^{2}$ School of Architecture, Building and Civil Engineering, Loughborough University, England, \\ UK \\ ${ }^{3}$ School of Civil and Construction Engineering, Oregon State University, Corvallis, USA
}

\begin{abstract}
:
In certain coastal areas across the globe, tsunamis pose a great threat to buildings, infrastructure and people's lives. The prevailing approaches for assessing building damage are based on probabilistic analysis. This paper introduces a new deterministic approach to assess large-scale building damage through quantifying lateral loading on structures induced by tsunami waves. A depth-averaged hydrodynamic model is adopted to simulate tsunami propagation and inundation and calculate the induced pressures and forces on structures. The model solves the 2D nonlinear shallow water equations (SWEs) using a finite volume shock-capturing numerical scheme and is implemented on Graphics Processing Units (GPUs) to achieve high-performance computing for large-scale applications. A new model component is included to calculate pressures and forces using the predicted flow variables, i.e. water depth and velocities. The output maximum tsunami forces are combined with a lateral force resisting system on each building to estimate the damage states. This new approach is developed by taking advantages of a similar damage assessment method and the corresponding coefficients for quantifying earthquake impact on buildings, due to the similarity between the horizontal force systems induced by the tsunami waves and earthquake motions. After being successfully validated against three experimental cases related to flow hydrodynamics, pressures and forces, the model is used to simulate a hypothetical 1000-year tsunami event in the City of Seaside, Oregon, USA. The resulting damage states are then classified for each of the urban buildings in the area, taking into account different building types. The predicted results are consistent with those obtained using alternative approaches, confirming the potential of the proposed approach for practical engineering applications.
\end{abstract}

Keywords: Tsunami modelling; Building damage assessment; Hydrodynamic force; Lateral force resisting system; Deterministic methods

\footnotetext{
* Corresponding author: Q.Liang@lboro.ac.uk
} 


\section{Introduction}

Tsunami represents a major type of natural hazards, and has long been perceived as extremely rare events. However, at least one damaging tsunami event per year has been reported in the past two decades (Bernard et al., 2010), which have caused tremendous death and economic loss along the coastlines across the globe. For example, triggered by an M9.3 undersea earthquake with an epicentre off the west coast of Sumatra, Indonesia, the 2004 Indian Ocean Tsunami inundated a large number of coastal communities with waves up to $30 \mathrm{~m}$ along the Indian Ocean coastline and killed 230,000 people in 14 countries. Approximately 96,000 buildings were destroyed in Sri Lanka alone (Leelawat et al., 2016). On 11th March 2011, the East Japan tsunami, triggered by the M9.0 Tohoku earthquake, caused over 15,000 deaths. The tsunami wave travelled up to $10 \mathrm{~km}$ inland with a maximum run of over $40 \mathrm{~m}$, causing 121,739 buildings totally collapsed and an addition of 279,088 buildings partially damaged, including nuclear power stations. It was also reported that more than 4,000 roads and bridges were destroyed or partially damaged during the event (Headquarters, 2016). Since 1990, fourteen tsunamis have been recorded to cause economic losses of more than USD 1 million, and the 2011 Japan tsunami has been recorded as the costliest tsunami disaster with a loss bill up to USD 220 billion (NGDC/WDS, 2016). These records indicate that tsunami poses a great threat to people and their properties in the coastal regions across the globe. It is an important and urgent task to develop reliable approaches and models to assess tsunami impact on the buildings and infrastructure to facilitate effective risk management, urban planning and building design.

In recent years, a growing number of models and approaches have been reported for assessing building damage induced by tsunamis. The early building damage assessment models were mainly developed based on empirical approaches. For example, the Papathoma Tsunami Vulnerability Assessment (PTVA) model was designed to provide a 'Relative Vulnerability Index' (RVI) score for every building in a given zone (Papathoma and Dominey-Howes, 2003). However, the PTVA model was developed in the absence of robust, well-constructed and validated building fragility models and may only be applied to provide first-order assessment of building vulnerability to tsunamis (Dall'Osso and Dominey-Howes, 2013; Dall'Osso et al., 2009). The model was later revised to become the so-called PTVA-3 model by further taking into account the effect of water intrusion and incorporating a multi-criteria approach (Dall'Osso and Dominey-Howes, 2013; Dall'Osso et al., 2009). However, without considering the detailed tsunami propagation and inundation processes, these models can only give subjective weighted scores for buildings in specific case studies.

With the rapid development of the remote sensing technologies, high-quality data have become much easier to collect and widely available after marine disasters. For example, the impacted buildings can now be more easily identified and the damage types can be classified by analysing satellite imageries that are taken before and after a specific event (Koshimura et al., 2009; Suppasri et al., 2012). Consequently, more sophisticated building damage assessment methods have begun to emerge, which may be generally divided into two 
categories: probabilistic methods and deterministic methods (Park et al., 2017). Based on statistical analysis to construct continuous functions reflecting the intensity of a hazardous event (X-axis) and damage response (Y-axis), probabilistic methods have been widely applied in practice due to their automatic account for the inherently uncertain nature of disastrous events and the complex interaction between structures and tsunami waves. These statistical functions are developed to give full expression of damage classifications, taking into account different factors including ground environments, building materials, construction codes and geographic locations. Damage curves and fragility curves/functions are the two main representations in the probabilistic methods (Tarbotton et al., 2015). Damage curves provide information about structural damage states related to the complete damage that buildings would incur (Kiefer and Willett, 1996; Reese et al., 2011). Reese et al. (2007) estimated damage ratios as a function of inundation depth and developed damage curves for timber, reinforced-concrete (RC) and brick buildings using a GPS-based approach after the 2006 South Java Tsunami. Based on a dataset collected for 1,535 buildings, Murao (2010) derived damage curves for non-solid and solid buildings in Sri Lanka and compared the results with those obtained from two sets of alternative damage curves previously developed in the same area.

Different from damage curves, fragility functions represent the conditional probability of damage that a building would receive during a given hazard level (Singhal and Kiremidjian, 1996). Statistical analysis and probability theory are the most fundamental approaches in deriving fragility functions. For example, Dias et al. (2009) used a cumulative frequency distribution function to compile 'completely damaged' housing units in southwest, north and east of Sri Lanka with tsunami height defined as a demand parameter. With the availability of rich sources of data, regression analysis has also been introduced to determine mean and standard deviations of normal or lognormal cumulative distribution functions in constructing fragility functions. Mas et al. (2012) used a standardized lognormal distribution function of inundation depth and linear least square regression technique to obtain fragility curves of structures in one of the worst hit towns, Dichato, during the 2010 Chilean Tsunami. More recently, Hatzikyriakou and Lin (2017) extended a likelihood function of maximum wave force potential and integrated with logistic regression analysis to estimate vulnerability and interdependency of different residential structures. These statistical methods commonly require substantial high-quality data to correlate damage states and building typologies. However, such high-quality datasets are not always available. Meanwhile, different techniques and assumptions are used in the process of deriving fragility functions, leading to inconsistent results that are difficult to be applied in different case studies (Tarbotton et al., 2015).

To facilitate probabilistic analysis, the intensity of the disastrous event being considered must be measured by a particular parameter, known as intensity measure (IM). Different IMs may be chosen in tsunami damage/risk assessment. Most of the early fragility functions used the maximum inundation depth as an IM (Mas et al., 2012; Suppasri et al., 2013). While the water 
depth is the easiest parameter to measure or predict, it cannot effectively reflect the dynamic interaction between tsunami waves and structures, which is an important factor causing damage and should be taken into account. Researchers have attempted to use momentum flux or hydrodynamic forces as IMs to perform damage assessment. Suppasri et al. (2011) developed relationships between building damage probability and inundation depth, current velocity, as well as hydrodynamic forces following the 2004 Indian Ocean tsunami in Thailand. Recently, Federal Emergency Management Agency (FEMA) developed momentum flux-based fragility curves for tsunamis. Park et al. (2017) employed these new fragility curves and specified the maximum momentum flux as an IM to estimate possible tsunami-induced building damage in Seaside, Oregon, USA. Attary et al. (2017) proposed a hybrid fragility function using both lateral forces and water depth as IMs for a three-story steel building in order to take into account the interaction between the flows and structures. Recently, Petrone et al. (2017) suggested that the peak tsunami force is a more effective IM than flow velocity and inundation depth in defining fragility curves.

Different from the probabilistic methods, the deterministic methods focus more on physically based theoretical analysis to directly correlate tsunami loading/forces to the corresponding structural response. However, the application of the deterministic methods has been restricted by the lack of understanding of the complex physical processes associated with extreme surge impacting structures and the high computational demand of simulating these processes, especially in large-scale applications. Therefore, few attempts have been made to use deterministic approaches to directly assess building damage. Dias et al. (2009) made a preliminary attempt to calculate the wave forces on detached buildings that are classified as 'complete damage'. But they only adopted simplified equations to estimate the tsunami-induced loads based on water depth. Although their wider application is currently limited, the deterministic approaches have a great potential to support direct building damage assessment in the real world if they are supported by advanced tsunami force quantification methods and directly linked to failure modes of structures.

The maximum force is often used to assess building damage in the deterministic methods. Therefore the peak tsunami force must be accurately calculated and a number of such attempts have been reported in the literature. Nistor et al. (2011) attempted to investigate the tsunami-induced hydrodynamic forces on a square column and a cylinder structure using laboratory experiments and numerical modelling with a smooth particle hydrodynamics (SPH) model. Robertson et al. (2011) carried out a series of laboratory experiments to quantify tsunami forces and pressures on structures using solitary waves propagating over a flat bottom and proposed a design formula for estimating maximum impact force by assuming that the impact was mainly imposed by the incoming surge. The Guidelines for Design of Structures for Vertical Evacuation (FEMA, 2012) suggested that the forces induced by tsunami waves may be classified into hydrostatic force, buoyant force, hydrodynamic force, impulsive force, debris impact force, debris damming force, uplift force and the additional gravity load from the retained water on elevated floors. FEMA (2012) also explained that not all of these tsunami 
loads affect a particular structural component at the same time. Yeh et al. (2014) analysed the time-varying combined force induced by tsunami waves and indicated that the most dangerous moment was when the first peak force directly acting on the front wall of a coastal structure, which is conventionally estimated to be 1.5 times of the subsequent hydrodynamic force (Attary et al., 2017; FEMA, 2012; Yeh et al., 2014). However, this assumption is not based on strong laboratory and field evidences and therefore the most dangerous maximum force is still largely undefined.

Research effort has also been made to investigate individual or combined fluid forces and their implications on building damage. Hayashi et al. (2012) evaluated the hydrostatic tsunami forces on a two-story steel building located in the Onagawa city during the 2011 Japan Tsunami, and suggested that the equally distributed hydrodynamic force might better explain the building's failure pattern. Yeh et al. (2013) attributed certain notable cases of structural failure in the 2011 Japan Tsunami to sufficient inundation depth, high flow speed, souring of foundation and strong uplifting force. Liang et al. (2016) further developed a two-dimensional shallow water hydrodynamic model to quantify the surge-induced hydrostatic and hydrodynamic pressure and impact on structures. Arimitsu and Kawasaki (2016) also proposed a similar method to reproduce the vertical distribution of the maximum tsunami wave pressure on a land structure, as measured in wave basin experiments. Tokimatsu et al. (2016) estimated the hydrodynamic and buoyant forces on five buildings in Onagawa using a 2D shallow water equation model, and linked the failure modes to sliding, uplift and overturning. Simulations have also been performed to assess the failure of bridges or breakwaters using fine-scale computational fluid dynamics (CFD) models (Bricker and Nakayama, 2014; Mori et al., 2015; Xu and Cai, 2015). However, all of the above studies have been focused on the analysis of tsunami forces on a single or a small number of buildings/structures and do not explicitly link the forces to the corresponding damage states.

A preliminary attempt to directly use mechanical analysis to assess building damage caused by a tsunami was made by Chock et al. (2013). They analysed the specific damage patterns on several buildings due to the lateral loading imposed by hydrostatic and hydrodynamic forces. They further compared tsunami loading with the inelastic structural seismic capacity of buildings in the Tohoku region through a lateral pushover analysis to classify building damage. The pushover analysis, based on a pushover curve obtained through nonlinear static force analysis, is a standard method for developing the relationship between the force and inelastic deformation at an arbitrary point. The structural response in terms of displacement may give better indicators than stress to relate the damage state to the degree of hazards (Ghobarah, 2001). The pushover curves, also known as building capacity curves, of the lateral force resisting system of a given structure hence provide a direct linkage between the forces and damage states (Villaverde, 2007). In current engineering practice, each building is designed with a lateral force resisting system to receive and safely transfer horizontal loads from winds or seismic movements to the foundation. The final components of all lateral forces induced by an earthquake or a tsunami are transferred to the lateral force resisting system through floor 
diaphragms (Attary et al., 2016). Therefore, the tsunami lateral loading acting on an initially intact building from external is similar to the horizontal earthquake forces imposed from the interior.

In seismic research, the nonlinear pushover method has been widely used to analyse the lateral force resisting system of inelastic buildings, facilitating structural response analysis and large-scale hazard assessment (Borzi et al., 2008). For example, the software Hazards United States Multi-Hazard (HAZUS-MH) released by FEMA provides various capacity curves for different building types and considers multiple scenarios involving different seismic levels (FEMA, 2011). HAZUS-MH is able to perform large-scale earthquake loss estimation in urban areas (Schneider and Schauer, 2006), and has been applied in several countries including India, Canada and America (Gulati, 2006; Neighbors et al., 2013; Ploeger et al., 2010). Tsunamis impact buildings on the lower level up to the inundation depth. The resulting forces, similar to the earthquake loads, simultaneously create bending moments and shear forces on the buildings. Attary et al. (2016) indicated that estimating the damage level of structures caused by a tsunami could be achieved using the seismic damage states available in HAZUS-MH. Park et al. (2017) adopted the fragility curve analysis in HAZUS-MH to assess tsunami damage. Attary et al. (2017) proposed a methodology to characterize the interaction between the structures and tsunami waves by utilizing the lateral force resisting system and building classification available in HAZUS-MH. Taking a three-story steel frame building as an example, their method uses empirical fragility functions and is not applicable to large-scale building damage assessment. As a whole, the lateral force resisting system has only been applied in tsunami damage assessment for a single or limited number of buildings; further research is needed to extend this approach to support large-scale building damage assessment across a whole city or region for urban planning and developing holistic risk management strategies. This requires high-resolution simulation of tsunami hydrodynamics and interaction with different types of buildings over large domains.

Simulation of tsunami events in large-scale urban environments is still a challenging task. Urban geometries have a great influence on flow hydrodynamics and must be represented in high resolution to produce accurate numerical predictions (Lynett, 2016). High-resolution tsunami simulation across a large domain, e.g. an entire city, is computationally too demanding in conventional computing hardware. In recent years, high-performance computing technologies, e.g. GPUs and Cloud, have experienced rapid development and been applied to accelerate CFD models for large-scale simulations. Particularly, GPUs have been used to improve the computational performance of hydrodynamic models that solve the shallow water equations (SWEs), which can be applied in tsunami modelling. Brodtkorb (2010) implemented three different finite volume shock-capturing numerical schemes on GPUs to numerically solve the SWEs. Smith and Liang (2013) presented a second-order finite-volume Godunov-type SWE model that can be flexibly used on different hardware devices, including most of the modern GPUs and central processing units (CPUs), for flood simulation. A similar numerical scheme has also been implemented on GPUs using the 
CUDA programming framework for whole-process tsunami modelling from wave propagation in deep water to flood inundation in dry lands (Amouzgar et al., 2016), which was then further extended to quantify the impacting forces induced by surge waves on structures at the laboratory scale (Xiong et al., 2016).

In this work, a new integrated modelling framework is presented to simulate the tsunami propagation and inundation processes and meanwhile directly assess building damage. The tsunami model solves the two-dimensional SWEs using a finite volume Godunov-type scheme to predict water depth and velocities, which are then used to quantify hydrostatic and hydrodynamic pressures as well as the corresponding forces induced by tsunami waves. The interaction between tsunami waves and buildings is then analysed using the building capacity curves of lateral force resisting systems and damage states from HAZUS-MH. Accelerated by high-performance modern GPUs, the model is able to support highly efficient tsunami simulation and damage assessment in large-scale applications. This paper is structured as follows: Section 2 introduces the numerical tsunami model and the method for deterministic building damage assessment; Section 3 validates the tsunami model using experimental data; in Section 4 the integrated model is applied to assess building damage caused by a hypothetic tsunami event in Seaside, Oregon, USA (Park et al., 2017; Park et al., 2013; Rueben et al., 2011); and finally brief conclusions are drawn in Section 5.

\section{Numerical Model}

This section introduces the proposed integrated modelling framework to simulate tsunami hydrodynamics and impact and assess large-scale building damage.

\subsection{High-performance hydrodynamic tsunami model}

The 2D non-linear SWEs are used to describe the hydrodynamic process of tsunami from propagation to inundation, which may be written in a matrix form as (Toro, 2001)

$$
\frac{\partial \mathbf{q}}{\partial t}+\frac{\partial \mathbf{f}}{\partial x}+\frac{\partial \mathbf{g}}{\partial y}=\mathbf{s}
$$

where $t, x$ and $y$ are the time and the two horizontal coordinates, respectively; $\mathbf{q}, \mathbf{f}, \mathbf{g}$ and $\mathbf{s}$ represent the vectors containing the flow variables, the $x$ and $y$-direction fluxes and the source terms. Neglecting the Coriolis effects and the surface stresses, the vectors may be given by (Liang and Borthwick, 2009) 


$$
\begin{array}{ll}
\mathbf{q}=\left[\begin{array}{c}
\eta \\
u h \\
v h
\end{array}\right] & \mathbf{f}=\left[\begin{array}{c}
u h \\
u^{2} h+g\left(\eta^{2}-2 \eta z_{b}\right) / 2 \\
u v h
\end{array}\right] \\
\mathbf{g}=\left[\begin{array}{c}
v h \\
u v h \\
v^{2} h+g\left(\eta^{2}-2 \eta z_{b}\right) / 2
\end{array}\right] \quad \mathbf{s}=\left[\begin{array}{c}
0 \\
-\tau_{b x} / \rho-g h \\
-\tau_{b y} / \rho z_{b} / \partial x \\
-g h
\end{array}\right]
\end{array}
$$

where $\eta$ and $h$ represent the water surface elevation above the datum (i.e. water level) and total water depth ( $h=\eta-z_{b}$ with $z_{b}$ defined as the bed elevation above the datum); $u$ and $v$ are the depth-averaged velocity components in the two Cartesian directions, respectively; $g$ is the acceleration due to gravity; $\rho$ denotes the water density; $-\partial z_{b} / \partial x$ and $-\partial z_{b} / \partial y$ define the bed slopes in the two Cartesian directions; and $\tau_{b x}$ and $\tau_{b y}$ are the bed friction stresses calculated from

$$
\tau_{b x}=\rho C_{f} u \sqrt{u^{2}+v^{2}} ; \quad \tau_{b y}=\rho C_{f} v \sqrt{u^{2}+v^{2}}
$$

where $C_{f}=\boldsymbol{g n}^{2} / \boldsymbol{h}^{1 / 3}$ is the bed roughness coefficient with $n$ being the Manning coefficient.

The above governing equations are solved using a finite volume Godunov-type shock-capturing numerical scheme, incorporated with an HLLC approximated Riemann solver to evaluate the interface fluxes. A two-step MUSCL-Hancock method is implemented to achieve 2nd-order numerical accuracy in both space and time. Detailed implementation of the numerical scheme can be found in Liang and Borthwick (2009) and Liang (2010). In order to substantially improve its computational efficiency for large-scale tsunami modeling, the model is implemented for GPU high-performance computing using the NVIDIA CUDA programing framework, which can be up to 40 times faster than its counterpart running on a standard CPU (refer to Amouzgar et al. (2016) for more details).

\subsection{Pressure and force calculation}

In this section, the flow variables (i.e. water depth and velocities) predicted by the SWE model are used to calculate the force caused by tsunami-induced hydrostatic and hydrodynamic actions. In open channel hydraulics, when assuming steady uniform flow with a uniform vertical velocity distribution, the total force function for a fluid section may be defined according to the momentum principle as

$$
F=P+\rho Q U
$$

where $P$ is the static pressure force; $Q$ is the total discharge through the fluid section; and $U$ is the depth-average velocity perpendicular to the stress surface, which is essentially equal to the flow velocity predicted by the SWE model along the same direction. When the flow is unsteady and non-uniform with dramatically varying velocities, it is necessary to introduce a correction factor $\beta$, i.e. momentum coefficient, to better estimate the average velocity. Eq. (4) is then revised as 
$F=P+\rho Q(\beta U)$

According to Chow (1959), $\beta$ is may be given as

$\beta=\left\{\begin{array}{ccl}1 & F r<1 & \text { (subcritical flow) } \\ 1.25 & F r>1 & \text { (supercritical flow) }\end{array}\right.$

where $F r$ is the local Froude number defined as $F r=U / \sqrt{g h}$.

Subsequently, the total pressure $p$ at an arbitrary point within the fluid section is given by

$p=p_{s}+p_{d}=\rho g z+\rho(\beta U)^{2}$

where $p_{s}$ and $p_{d}$ are the static and dynamic components of the point pressure, respectively; and $z$ is the depth from water surface to the point of interest. The total force, $F_{T}$, induced by the flow on a vertical rectangular cross-section (assume width $B$ ) is then calculated by

$F_{T}=\int_{B} \frac{1}{2} \rho g h_{i}^{2} d B+\int_{B} \rho\left(\beta U_{i}\right)^{2} h_{i} d B$

With the flow depth and velocities available from the aforementioned hydrodynamic tsunami model, Eq. (7) and Eq. (8) are applied to calculate the static and dynamic components of the pressure and total force acting on a structural wall in each grid cell at each time step.

\subsection{Building Damage Assessment}

In order to reflect structural response, the damage states and pushover analysis of the lateral force resisting system of HAZUS-MH are introduced into the current model for building damage assessment in tsunami-affected areas. HAZUS-MH defines four building damage states, i.e. 'Slight', 'Moderate', 'Extensive', and 'Complete', as described in detail in its Technical Manual (FEMA, 2011). Meanwhile, HAZUS-MH classifies buildings into 36 basic types, depending on their primary functions (e.g. commercial or residential) and constructive conditions (e.g. floors and materials such as wood, RC, steel, etc.). Each building type is then subdivided into four design levels (i.e. 'Pre-Code', 'Low-Code', 'Moderate-code' and 'High-Code'). In total, HAZUS-MH provides 144 pushover/capacity curves based on the lateral-force design requirements for various buildings.

The building capacity curves are controlled by design capacity, yield capacity and ultimate capacity. Design capacity represents the nominal building strength required by the seismic code or an estimated nominal strength according to different design requirements, e.g. the wind force or lateral tsunami loading (Kircher et al., 2006). Yield capacity represents the actual lateral strength of a building considering redundancies in the design, and also the actual strength of materials. Ultimate capacity represents the maximum strength of a building when the global structural system has reached the maximum deformation state. Buildings are assumed to be capable of deforming beyond their ultimate point, but their structural systems 
provide no additional resistance to lateral force. The coefficients of above three capacities are denoted as $C_{s}$ for the design strength as a fraction of building weight, $\gamma$ for the yield strength as a fraction of design strength, and $\lambda$ for ultimate strength as a fraction of yield strength. The values of the coefficients for different building types are tabulated in the Technical Manual of HAZUS-MH (FEMA, 2011).

In order to integrate the capacity curves of lateral force resisting systems to the tsunami model, the weight of each building must be firstly estimated by

$$
W_{i}=k A_{i} H_{i} \rho_{b i} g / \alpha_{1}
$$

where the subscript $i$ gives the index of buildings, $A$ represents the building area, $\rho_{b}$ is the density of the building materials, $k$ denotes the ratio between the volume of building materials and the total volume of building expressed as a percentage (25\% in this work), $H$ is the building height from floor to roof, and the weight factor, $\alpha_{l}$, is an effective fraction of building weight in the pushover analysis of HAZUS-MH. Typical values of both $H$ and $\alpha_{1}$ are suggested in FEMA (2011) for different building types.

Table 1: Coefficients for different building types.

\begin{tabular}{l|r|r|r|r|r|r|r|c}
\hline \multirow{2}{*}{$\begin{array}{c}\text { Building } \\
\text { Type }\end{array}$} & \multirow{2}{*}{$\begin{array}{c}\mathrm{H} \\
(\mathrm{m})\end{array}$} & \multirow{2}{*}{$\alpha_{1}$} & \multicolumn{4}{|c|}{$\mathrm{C}_{\mathrm{s}}$} & \multirow{2}{*}{$\gamma$} & \multirow{2}{*}{$\lambda$} \\
\cline { 5 - 8 } & & High-Code & Moderate-Code & Low-Code & Pre-Code & & \\
\hline W1 & 4.27 & 0.75 & 0.200 & 0.150 & 0.100 & 0.100 & 1.50 & 3.00 \\
\hline W2 & 7.33 & 0.75 & 0.200 & 0.100 & 0.050 & 0.050 & 1.50 & 2.50 \\
\hline C1-Low & 6.10 & 0.80 & 0.200 & 0.100 & 0.050 & 0.050 & 1.50 & 3.00 \\
\hline C1-Mid & 15.24 & 0.80 & 0.200 & 0.100 & 0.050 & 0.050 & 1.25 & 3.00 \\
\hline C1-High & 36.58 & 0.75 & 0.150 & 0.075 & 0.038 & 0.038 & 1.10 & 3.00 \\
\hline
\end{tabular}

The values of all the coefficients related to the building types involved in the current work are listed in Table 1 (FEMA, 2011). The common buildings are classified into three types: W1, W2 and C1. W1 and W2 are timber buildings in different areas and of different storeys, of which the density is assumed to be $750 \mathrm{~kg} / \mathrm{m}^{3}$. W1 contains all the detached residential buildings, and W2 includes both the terrace residential buildings and certain small commercial buildings. C1 represents the RC commercial buildings, such as hotel, condominium or parking structure, and the density is assumed to be $2400 \mathrm{~kg} / \mathrm{m}^{3}$ in simulation. According to the building floors, three categories are further defined: 1 - 3 floors as Low-rise, 4 - 7 floors as Mid-rise and more than 7 as High-rise. The building seismic design codes are decomposed into four levels, i.e. Pre-Code, Low-Code, Moderate-Code and High-Code, for different years as applied.

When assessing building damage, the aforementioned capacity coefficients $C_{s}, \gamma$ and $\lambda$ are multiplied by $W_{i}$ to determine building's design capacity, yield capacity and ultimate capacity. These capacity levels of a building are used to compare with the maximum tsunami 
force $\left(F_{T \max }\right)$ received by the building, i.e. the maximum output from Eq. (8) during a simulation, to define the corresponding damage patterns, as defined in Table 2.

Table 2: Building damage patterns defined using maximum tsunami force.

\begin{tabular}{ll}
\hline Maximum Tsunami Force & Damage Level \\
\hline$F_{T \max }=0$ & No Damage \\
\hline $0<F_{T \max } \leq C_{s} W_{i}$ & Slight Damage \\
\hline$C_{s} W_{i}<F_{T \max } \leq \gamma C_{s} W_{i}$ & Moderate Damage \\
\hline$\gamma C_{s} W_{i}<F_{T \max } \leq \lambda \gamma C_{s} W_{i}$ & Extensive Damage \\
\hline$\lambda \gamma C_{s} W_{i}<F_{T \max }$ & Complete Damage \\
\hline
\end{tabular}

\section{Model Validation}

The success of the proposed deterministic building assessment model relies on accurate estimation of the tsunami-induced hydrostatic and hydrodynamic forces acting on buildings. In this section, three experimental tests are considered to validate the present model for accurate calculation of tsunami impact pressures and forces. The model's capability in predicting tsunami hydrodynamics has been validated and confirmed in Amouzgar et al. (2016).

\subsection{Auckland flume experiments}

Shafiei et al. (2016) investigated the interaction between tsunami waves and coastal structures using physical experiments. The experiments were conducted in a concrete wave flume of $14 \mathrm{~m}$ long, $1.2 \mathrm{~m}$ wide and $0.8 \mathrm{~m}$ deep. Upstream of the flume, an automatic vertical-rise sliding gate was instantaneously opened to release water from the reservoir behind, forming a dam-break wave which is hydraulically similar to a tsunami bore (Chanson, 2006). As illustrated in Fig. 1, five capacitance-type wave gauges were placed along the central line of the flume to record the time series of water level, labelled $1 \sim 5$ from left to right. A $300 \mathrm{~mm} \times 300 \mathrm{~mm} \times 600 \mathrm{~mm}$ square-prism model structure was placed at $10 \mathrm{~m}$ downstream of the gate. The pressures on the front wall of the structure were recorded using five pressure sensors, labelled $1 \sim 5$ from bottom to top. A series of dry-bed experiments were carried out with different combinations of gate opening height (GO) and reservoir water depth (WL). The case with GO $=300 \mathrm{~mm}$ and $\mathrm{WL}=$ $600 \mathrm{~mm}$ generated the maximum pressure and is considered herein. The resulting bore height was $210 \mathrm{~mm}$, taken as the mean of five repeating measurements (Shafiei et al., 2016). 


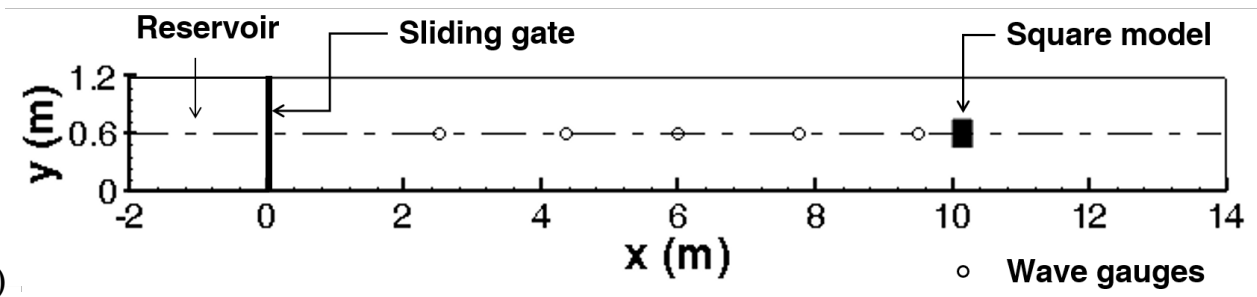

(a)

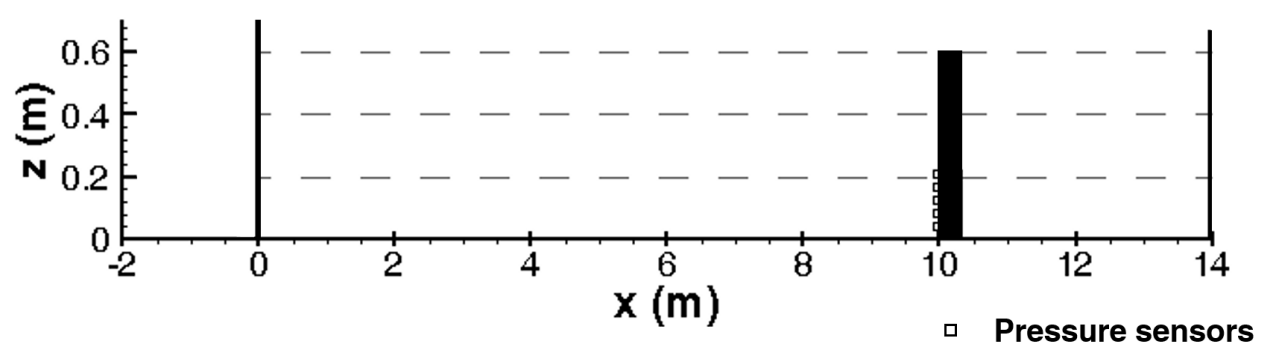

(b)

Fig. 1 Layout of the flume: (a) plan view; (b) side view. The locations of wave gauges and pressure sensors are respectively indicated using hollow circles and squares in the plots.

In the simulation, the computational domain covers the entire $14 \mathrm{~m} \times 1.2 \mathrm{~m}$ flume and is discretised using a uniform grid with square cells of $0.01 \mathrm{~m}$ resolution. A constant Manning coefficient of 0.021 is applied over the whole domain for rough concrete flume bed (Wei and Jia, 2014). The sliding gate remains open for 4 seconds at the beginning of the simulation and then automatically closes with a closing time of $0.46 \mathrm{~s}$, as happened during the experiment. The water level in the reservoir is assumed to be constant during the whole process. Since the water depth at the gate, $e$, is less than the water level $H$ behind the gate (in the reservoir), the discharge per unit width, $q$, may be calculated using submerged culvert flow formula (Zhao and He, 2010)

$q=\mu e \sqrt{2 g(H-\mu e)}$

where $\mu$ is the contraction coefficient related to the gate opening and the radio between $e$ and $H$, which is set to change with $\boldsymbol{e} / \boldsymbol{H}$ during the lifting period, and fixed to 0.59 when the gate reaches its final position. The gate is treated as an open boundary with an inflow calculated by Eq. (10) at the first $4 \mathrm{~s}$ when the gate is opened, and then a solid boundary after it is fully closed.

The experimental measurements and numerical results are presented and compared in Fig. 2 and Fig. 3. In Fig. 2, the time histories of water depth recorded at the five wave gauges are presented. The numerical results are observed to correctly capture the change of water depth along the flume from wave gauge 1 to wave gauge 4, demonstrating the model's capability in reproducing the tsunami hydrodynamics. At wave gauge 5, the water level predicted by the model is much bigger than the measurement after $4.95 \mathrm{~s}$. In the experiment, the propagating bore was observed to break in front of the structure but the current SWE model does not specifically account for the substantial energy dissipation caused by wave breaking and may therefore predict higher water level. 
(a)

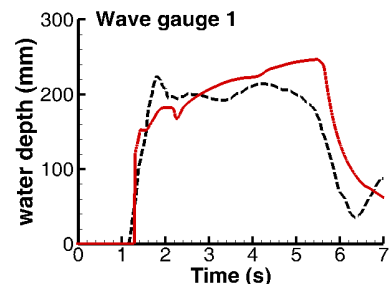

(d)

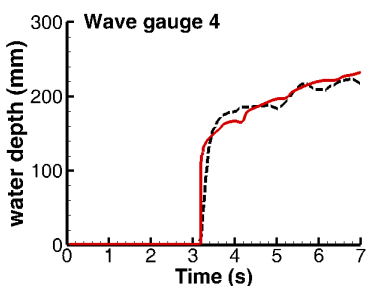

(b)

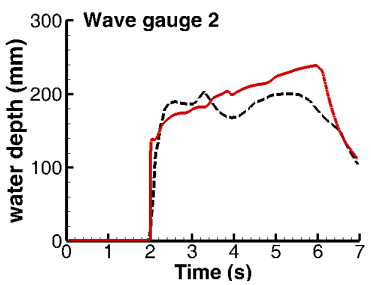

(c)

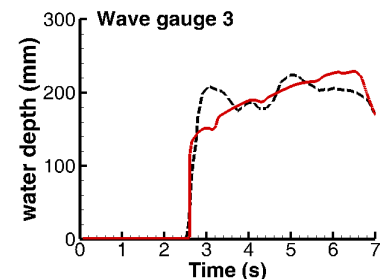

(e)

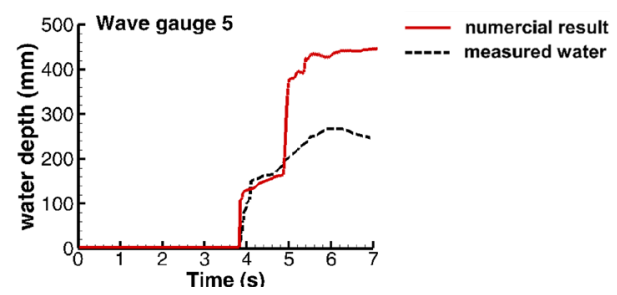

Fig. 2 Calculated and measured time histories of water depth at the five wave gauges.

Fig. 3 compares the numerical pressure profiles calculated by Eq. (7) with those measured by the five pressure sensors attached to the structure (measured at $1000 \mathrm{~Hz}$ frequency). The numerical results agree satisfactorily with the measurements. The first impulsive pressure is well captured in the first four pressure gauges. At the pressure gauge 5 installed in the upper part of the structure, the predicted impulsive pressure is found to be slightly larger and more evident than the measured values. The quasi-steady states of the pressure following the peaks are correctly captured in all gauges.

(a)

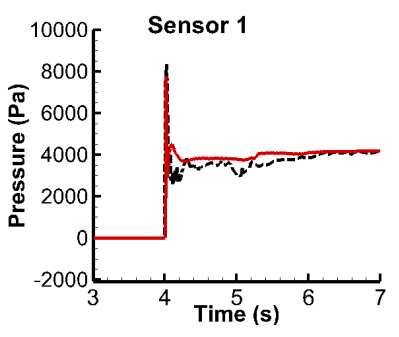

(d)

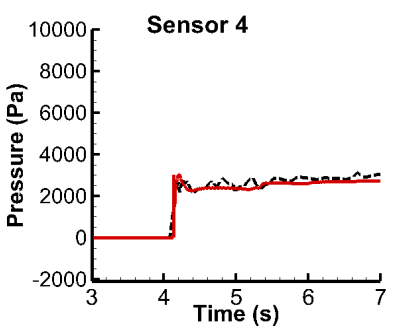

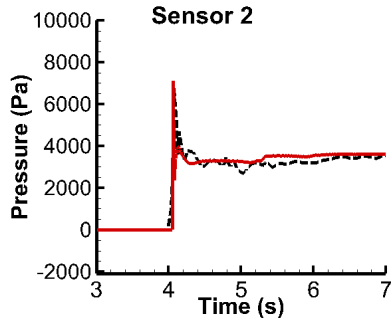

(c)
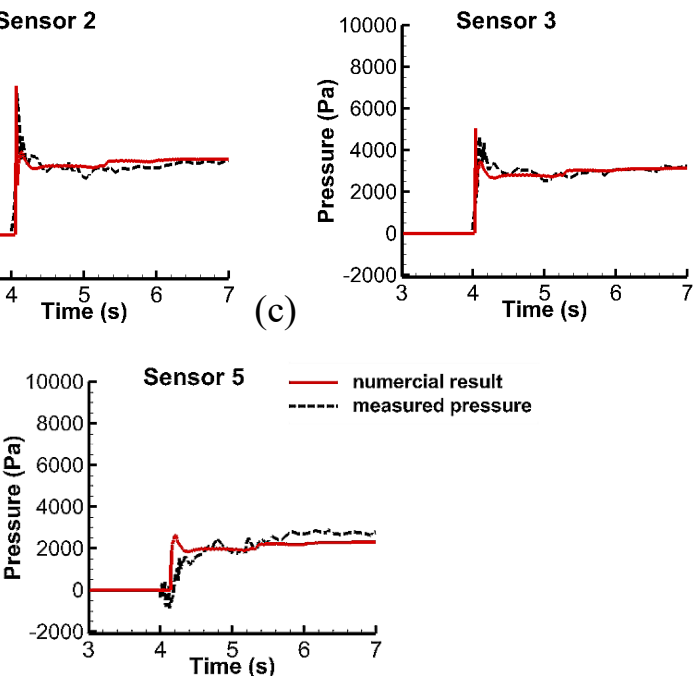

Fig. 3 Calculated and measured pressure profiles at the five pressure sensors.

\subsection{Oregon flume experiments}

Santo and Robertson (2010) performed a series of experimental tests in the Tsunami Wave Basin (TWB) in the O.H. Hinsdale Wave Research Laboratory at the Oregon State University. The flume was constructed in TWB with concrete masonry walls, which is $2.1 \mathrm{~m}$ wide and 48.8 $\mathrm{m}$ long with a constant 1:5 slope installed in the middle to connect the lower and higher beds, as shown in Fig. 4. The initial water level was set to be $1 \mathrm{~m}$ during the experiments. A piston-type 
wave maker was set up on the left boundary of the flume and used to create a solidary wave. The solidary wave developed into a violent bore after reaching the slope, imposing similar loading on a structure as a tsunami bore does. A $0.3 \mathrm{~m} \times 0.05 \mathrm{~m}$ rectangular column structure supported by two load cells (measuring forces at $1000 \mathrm{~Hz}$ frequency) was placed on the dry flat section of the flume, which was $35 \mathrm{~m}$ away from the wave maker. The generated wave propagated to downstream and hit the structure after passing the slope. The forces acting on the column structure are recorded for the experiments with three different wave heights, i.e. $0.2 \mathrm{~m}$, $0.4 \mathrm{~m}$ and $0.6 \mathrm{~m}$, respectively. During the numerical simulations, the domain is discretised using a uniform grid of square cells at $0.05 \mathrm{~m}$ resolution. The Manning coefficient is set to 0.016, a typical value for exposed concrete slope (Wei and Jia, 2014). A solitary wave profile (generated by the wave maker) is imposed at the left-hand-side flume boundary (Rueben et al., 2011; Xiong et al., 2016) to create the tsunami bore and other domain boundaries are assumed to be close.

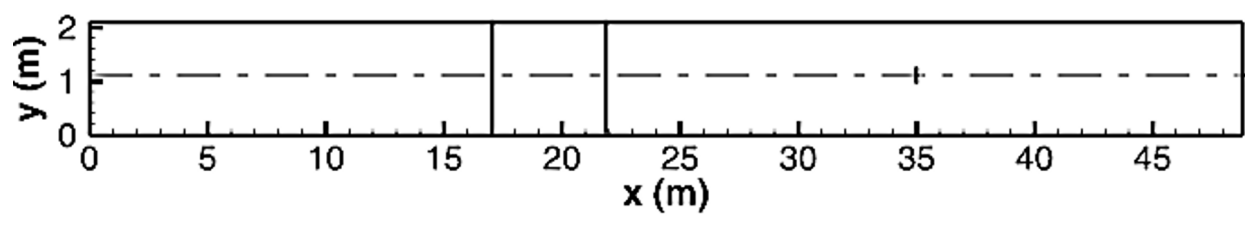

(a)

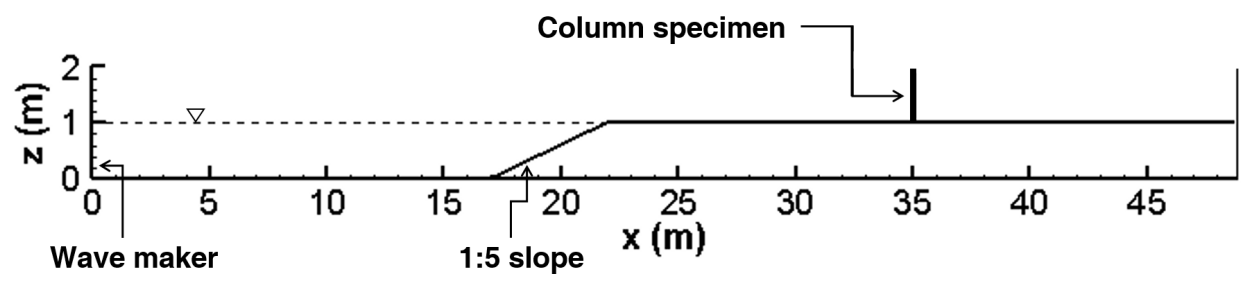

(b)

Wave make

Fig. 4 Flume and experimental set up: (a) plan view; (b) side view.

(a)
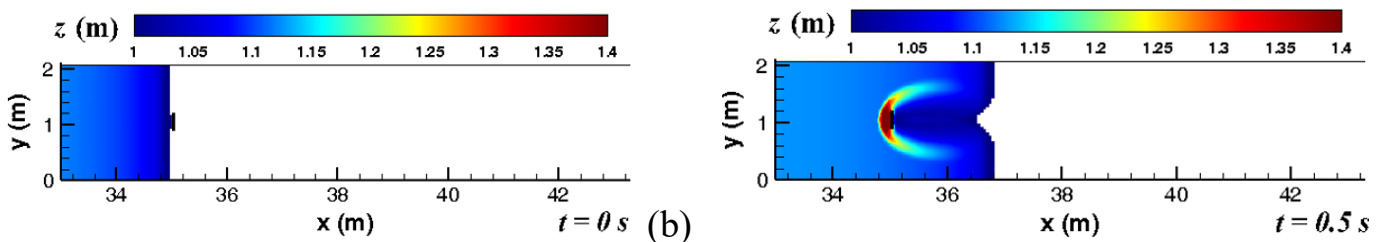

(c)

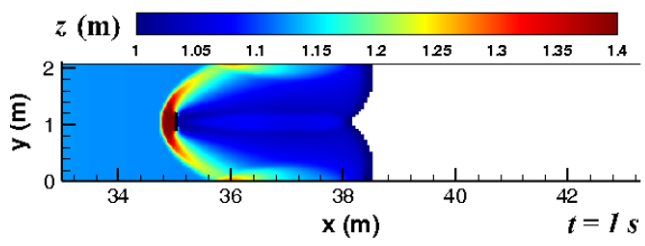

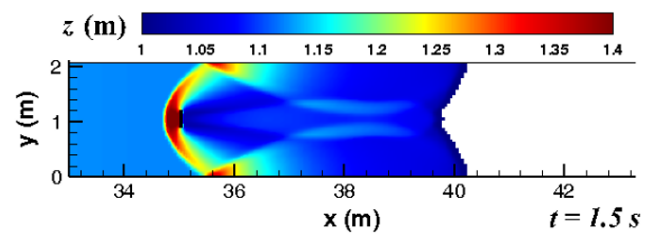


(e)
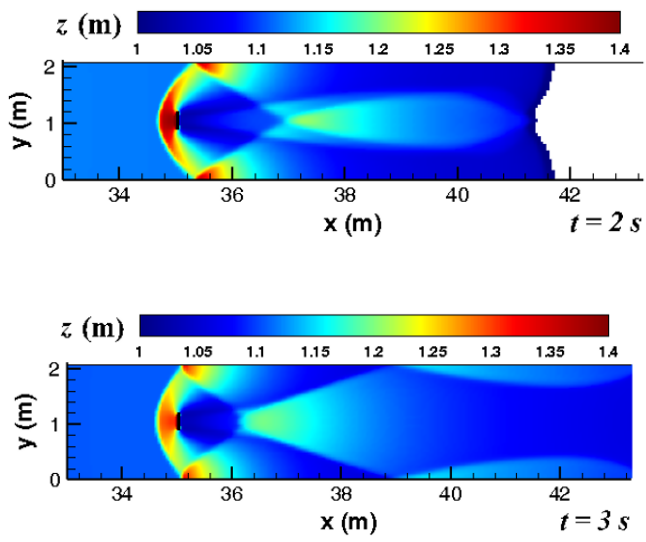

(f)

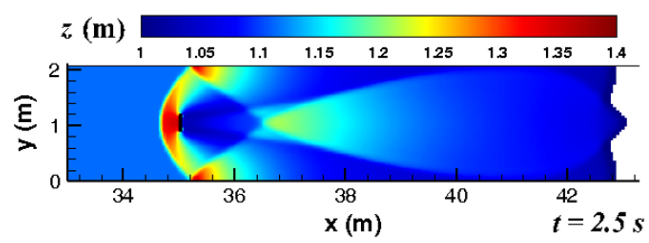

(h)

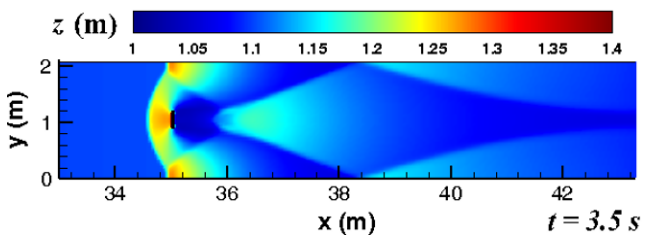

Fig. 5 Wave-structure interaction at: (a) $t=0 \mathrm{~s}$ when the wave just hits the structure; (b) $t=$ $0.5 \mathrm{~s}$; (c) $t=1 \mathrm{~s}$; (d) $t=1.5 \mathrm{~s}$; (e) $t=2 \mathrm{~s}$; (f) $t=2.5 \mathrm{~s}$; (g) $t=3 \mathrm{~s}$; (h) $t=3.5 \mathrm{~s}$.

Fig. 5 depicts the plan-view of the predicted water level and wave patterns at eight different output times. In this case, the incident wave has a wave height of $0.6 \mathrm{~m}$. In the plots, the structure is represented by a black rectangle. Fig. 6 illustrates the calculated and measured time histories of the hydrodynamic loads on the column structure, with $t=0 \mathrm{~s}$ indicating the moment when impact just starts. Herein, the forces on the front and back walls of the structure are calculated using the integral form of Eq. (8), and the difference is considered as the total force acting on the structure. In all of the three experiments with different wave heights, the rising limbs of the profiles and the biggest forces are all well predicted and agree satisfactorily with measurements. However, discrepancies are observed in the falling limbs and the predicted forces appear to fall more slowly, especially for the case with a $0.6 \mathrm{~m}$ incident wave height. A possible reason may be because wave dispersion is not taken into account in the current SWE model. Overall, the current model has accurately captured the maximum impact force and time, which is more important for engineering applications.

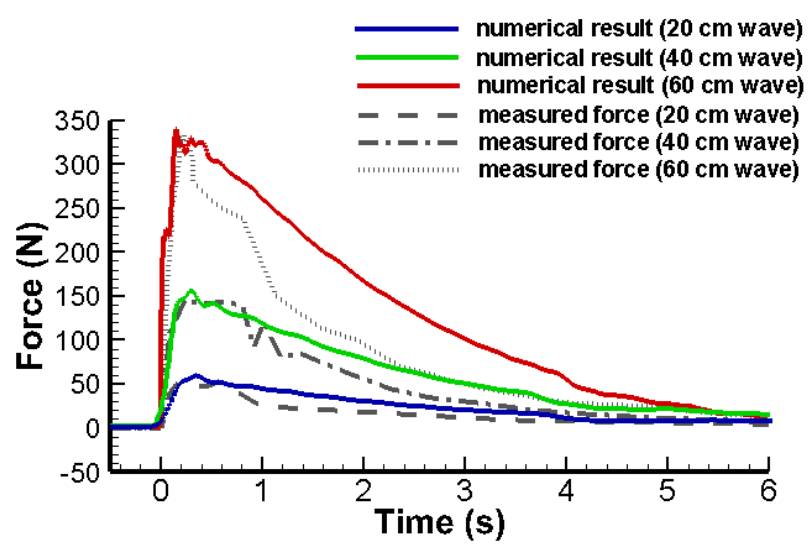

Fig. 6 Calculated and measured time histories of the loads on the column structure.

\subsection{Experiments of tsunami forces on square column structure}

Nistor et al. (2011) conducted experiments on hydraulic bores impacting a structure in the Canadian Hydraulics Centre of the National Research Council of Canada (Nouri et al., 2010). 
As shown in Fig. 7, the stainless steel flume with glass walls was $10.6 \mathrm{~m}$ long, $2.7 \mathrm{~m}$ wide and $1.4 \mathrm{~m}$ deep; a drain was equipped at the end (right) of the flume to allow free discharge. The upstream reservoir was filled with water of specified depths. A hinged gate was installed to separate the reservoir and downstream section of the flume. The gate was rapidly opened to release water and create a dam-break bore propagating downstream and hitting the column structure. A load cell with six degrees of freedom was fixed beneath the base of the structure to measure the loads generated from the hydraulic bore impact.

(a)

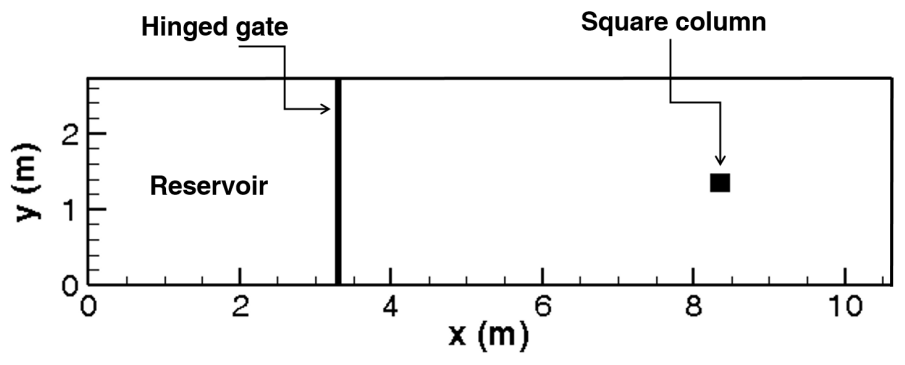

(b)

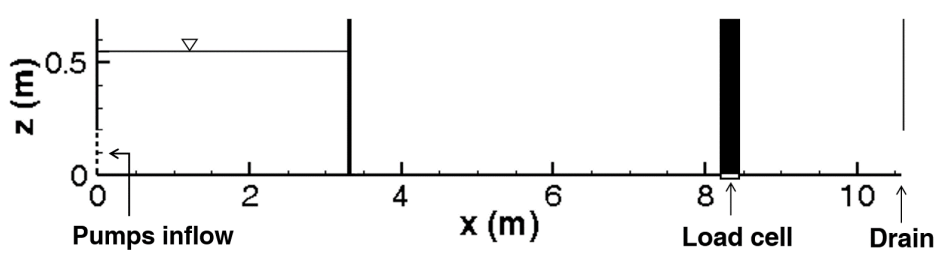

Fig. 7 Layout of the flume: (a) plan view; (b) side view.

Herein, the experiment with an initial impoundment depth of $0.55 \mathrm{~m}$ is considered and simulated using the present model. The computational domain, covering both the reservoir and the downstream flume section, is discretised using a uniform grid with square cells of $0.05 \mathrm{~m}$ resolution. The Manning coefficient is set to 0.01 for the whole domain to represent smooth stainless steel surface. The left boundary of the computational domain is set to be open with a steady inflow discharge of $0.78 \mathrm{~m}^{3} / \mathrm{s}$, which was maintained by pumps in the experiments (Nouri et al., 2010). The right boundary of the domain is open to allow free discharge. Close/reflective boundaries are imposed for the two sidewalls.

Fig. 8 presents the calculated and measured forces acting on the column structure. The force reaches a peak immediately after the impact, and then decline to reach a quasi-steady state. The numerical result well predicts the maximum force, but slightly overestimates the force immediately after the impact as a result of neglecting wave dispersion in the current tsunami model. Generally, the numerical simulation captures reasonably well the peak force and the overall declining process, confirming the capability of the model in predicting tsunami induced forces, particularly the maximum forces, on structures. 


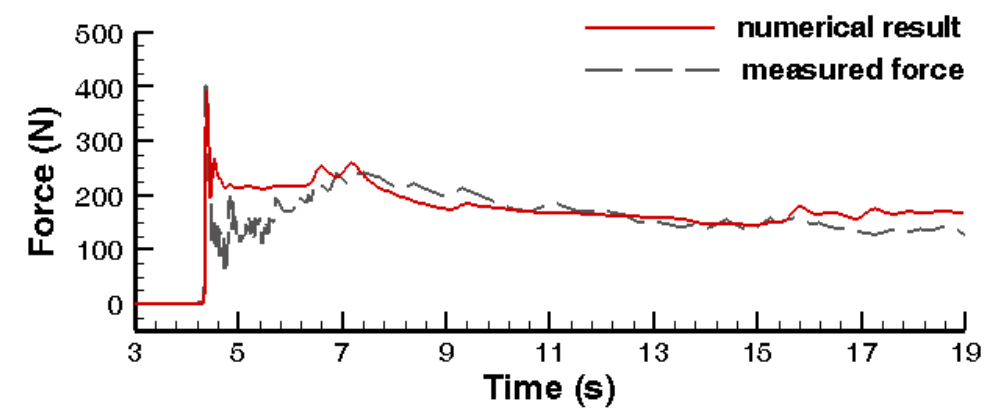

Fig. 8 Calculated and measured time histories of the hydraulic forces on the column structure.

\section{Case Study}

In this section, the proposed modelling system is applied to assess building damage caused by a hypothetic tsunami event in Seaside, Oregon, USA. The selected case study site has a relatively simple bathymetry featured with parallel shore contours, and is potentially exposed to high risk of tsunami (Park et al., 2017). Particularly, there are several large hotels and commercial buildings near to the beach, further highlighting the importance of evaluating tsunami impacts and developing disaster mitigation strategies. This case study has been considered by several other researchers, providing a rich source of data including detailed experiment measurements and alternative numerical results to support the current study.

\subsection{Model setup}

The selected case study site has been investigated previously for tsunami inundation and probabilistic building damage estimation (Park et al., 2013; Wiebe and Cox, 2014). The Google Earth satellite image in Fig. 9(a) shows the region from $123.896^{\circ} \mathrm{W}$ to $124.015^{\circ} \mathrm{W}$ and $45.955^{\circ} \mathrm{N}$ to $46.045^{\circ} \mathrm{N}$. The white rectangle in Fig. 9(a) highlights the area with the most concentrated buildings and population in Seaside, and therefore it is most vulnerable to a tsunami attack. Fig. 9 also marks two gauge points, i.e. Point $\mathrm{A}\left(124.011^{\circ} \mathrm{W}, 46^{\circ} \mathrm{N}\right.$ near the seaward boundary) and Point $\mathrm{B}\left(123.931^{\circ} \mathrm{W}, 45.995^{\circ} \mathrm{N}\right.$ on the shoreline) to record and compare time series of water surface elevation during the simulations. In the central area of Seaside, two rivers separate the city from the coast to the inland into three parts, which will have a predominant effect on the tsunami inundation process (Rueben et al., 2011). The DEM of the 9,920 $\mathrm{m} \times$ 7,776 $\mathrm{m}$ computational domain is shown in Fig. 9(b). The black solid lines indicate the shoreline at the mean sea level. During the numerical simulations, the domain is discretised using a uniform grid with $1240 \times 972$ cells. A constant Manning coefficient of 0.03 is used across the entire domain. The four domain boundaries are all set to open to allow free discharge to better reflect the actual situation. The varying water elevations at Point A (close to the left boundary of the domain), provided in Park and Cox (2016), are used as the boundary conditions to drive a tsunami event through the left/west domain boundary. 
(a)

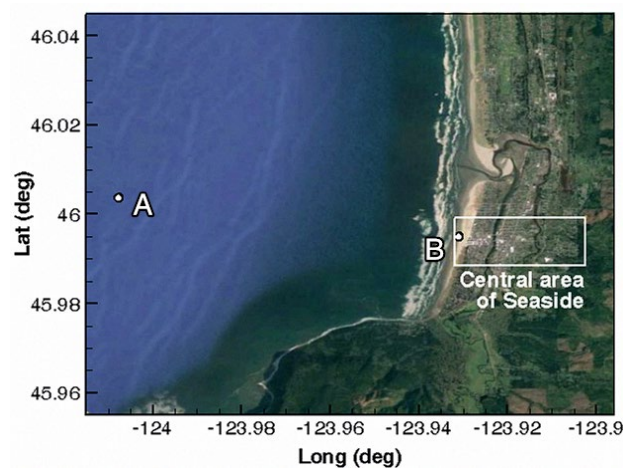

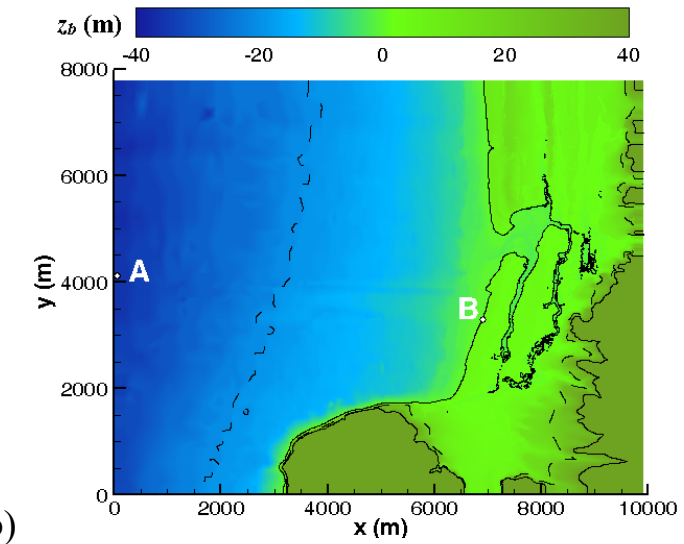

(b)

Fig. 9 (a) Satellite image of the coastal area and the city of Seaside; (b) DEM of the domain.

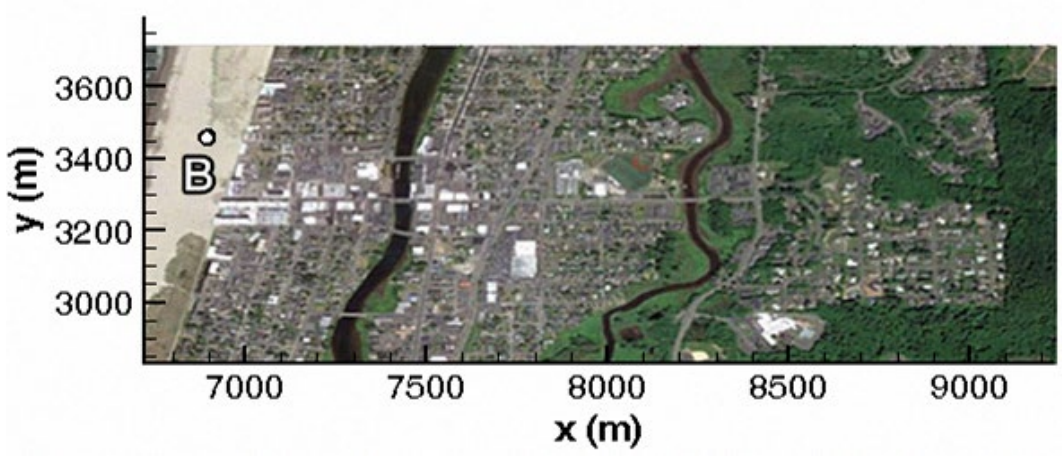

(a)

$$
x(m)
$$

(b)

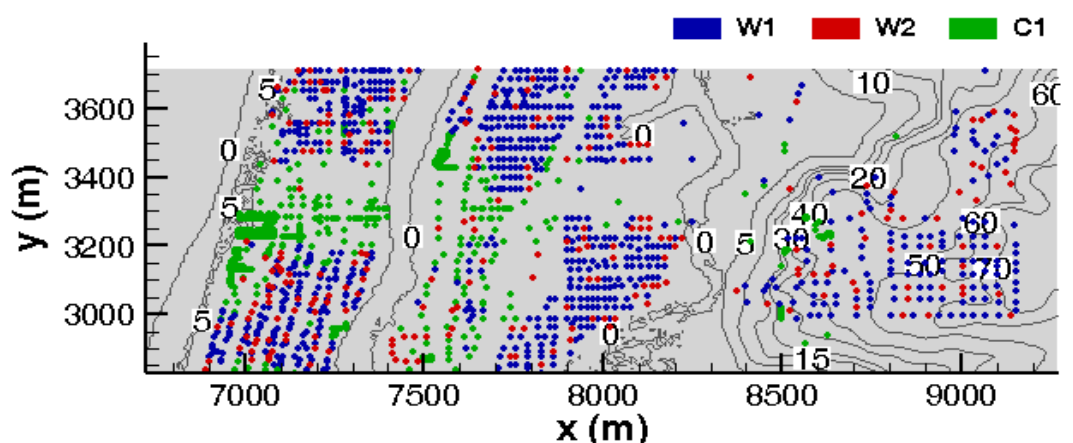

Fig. 10 (a) Satellite image of the central area of Seaside; (b) building type classification map.

The building information in the city is available to the current study, including the UTM coordinates, floors, design codes, elevations and tax lot data for each of the buildings. The satellite image of the buildings in the central area of Seaside is presented in Fig. 10(a). The coordinates of buildings have been transferred and used to mark their locations on the DEM, as presented in Fig. 10(b). In Fig. 10(b), the darker grey lines with labels are the ground level contours from $0 \mathrm{~m}$ to $70 \mathrm{~m}$ and the two rivers as mentioned before are bounded by the $0 \mathrm{~m}$ contour lines winding around $x=7400 \mathrm{~m}$ and $x=8300 \mathrm{~m}$. Fig. 10(b) also shows a map of building types, indicted by points in different colours. All relevant data of a building (e.g. building design codes, tax lot data, etc.) are stored in the corresponding cells of the computational grid where the building is located. The elevations of the corresponding raster 
DEM cells have also been corrected using the building heights. The hydrodynamic tsunami model is run on the corrected DEM to capture the shielding phenomenon created by the dense buildings. Meanwhile, the floor information is also recorded to avoid repeated calculation of the building areas for multi-storey buildings.

Specifically, the tax lot data contain detailed information about the properties on each lot (the smallest unit) for tax assessment purposes. However, these data are assigned to all buildings on the same tax lot, but not individual buildings (Howard et al., 2012; McDonnell et al., 2011). To process the tax lot data for use in the proposed building damage assessment framework, three assumptions are made. Firstly, only one building is assumed to exist on each lot. The assumption of one building in each lot is consistent with the building layouts on the satellite map and will not significantly affect the reliability of the overall damage assessment in the city area. Secondly, the building area is assumed to be the same as the tax lot area. Normally, the tax lot area is equal to the building area for those single-purpose buildings, but this may not be the case if a lot contains multi-purpose buildings. Table 3 lists the purposes, numbers and percentages of all three types of buildings in the central area of Seaside. Building(s) in a tax lot may be categorised in to three different types, i.e. residential buildings (W1), commercial building (C1) and mixed residential and commercial buildings (W2). Obviously only the multi-purpose buildings (W2) would have different building and tax lot areas. The number of these buildings is relatively small (17\%) and they are scattered in the central area. Therefore, the assumption of tax lot area equal to the building area for all buildings is reasonable and will not affect the overall accuracy of the proposed building assessment exercise. Finally, the shape of all buildings is assumed to be square to facilitate easy estimation of building width $B$ in Eq. (8). In reality, buildings may also be rectangular with long or short sides in different orientations and of different shapes. The sensitivity of the damage assessment results to building width will be investigated later to validate and confirm this assumption.

Table 3: Number and percentage of the three types of buildings in central Seaside.

\begin{tabular}{c|c|c|c|c}
\hline Building Type & W1 & W2 & C1 & Total \\
\hline Purpose & Residential & $\begin{array}{c}\text { Residential, } \\
\text { Commercial }\end{array}$ & Commercial & \\
\hline Number & 750 & 242 & 426 & 1418 \\
\hline Percentage (\%) & 52.9 & 17.06 & 30.04 & 100 \\
\hline
\end{tabular}

All of the simulations are run on a NVIDIA Tesla K80 GPU and require $\sim 30-40$ minutes of runtime for the 180-minute event. During a simulation, the model outputs the predicted flow depth, velocities, pressures, forces and building damage results at a prescribed time interval.

\subsection{Tsunami hydrodynamics}

Fig. 11(a) shows the time series of water elevation at gauge Points A and B for the hypothetic tsunami event with a 1000-year return period as also considered in Park et al. (2017). 
Consistent with the inflow conditions, the first tsunami peak appears at Point A after approx. 30 minutes and arrives at Point B 8 minutes later. The corresponding time history of flow velocity at Point B is illustrated in Fig. 11(b). The maximum water elevation $h_{\max }$ and flow momentum $\left(h u^{2}\right)_{\max }$ are recorded in each of the computational cells and plotted in Fig. 12. The areas in light blue represent the sea and rivers and are not relevant to the damage assessment. Fig. 12(b)\&(d) present the zoom-in plots of $h_{\max }$ and $\left(h u^{2}\right)_{\max }$ in the central Seaside, which is the focused area for building damage assessment in this work. The value of $h_{\max }$ reaches the maximum at the shoreline (the water depth in the sea is disregarded for analysis), and gradually decreases inland. In the two rivers, compared to the west banks, the water levels slightly increase at the east banks, which is a phenomenon caused by existing water in the rivers. The value of $\left(h u^{2}\right)_{\max }$ also reaches the maximum approximately at the shoreline, maintains for a distance towards inland, and then dramatically declines to the minimum as a result of energy dissipation. The present results are consistent and compared well with those presented in Park et al. (2017), in which ComMIT/MOST model and COULWAVE model were used to simulate the tsunami propagation and inundation. Due to the highly transient nature of tsunami wave propagation, the distributions of the maximum water depth and maximum momentum are apparently different, as shown in Fig. 12. As a result, the traditional building damage assessment methods using water depth and momentum as IMs may predict to different results.

(a)

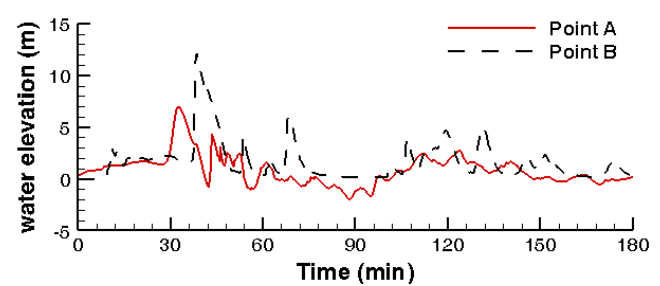

(b)

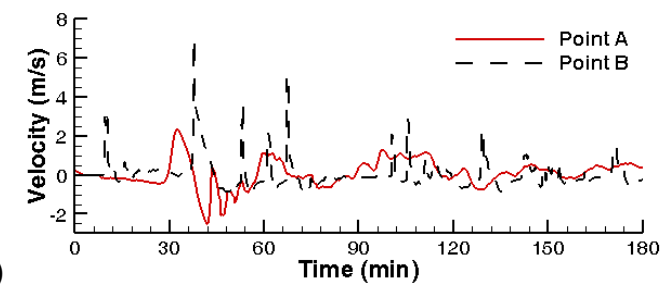

Fig. 11 Time series of (a) water elevation at Point A and Point B; (b) flow velocity at Point A and Point B.

(a)

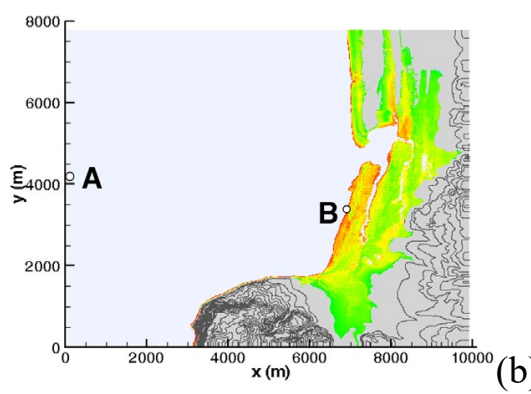

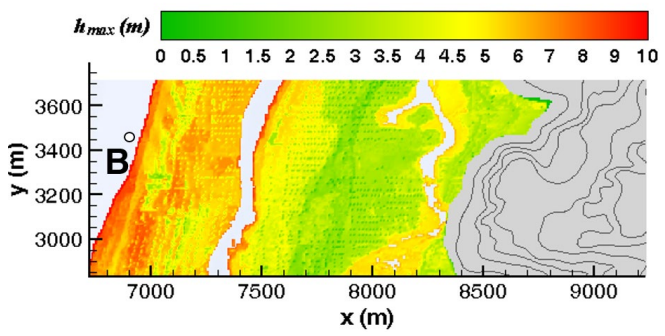


(c)

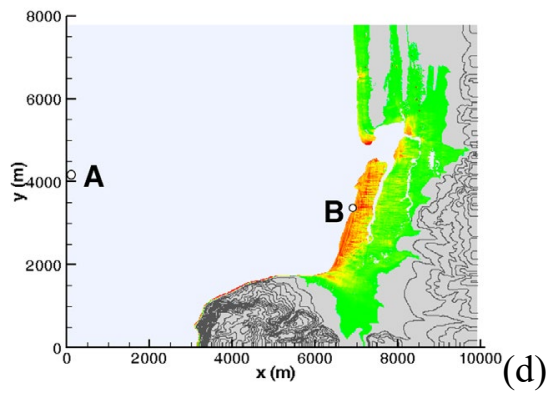

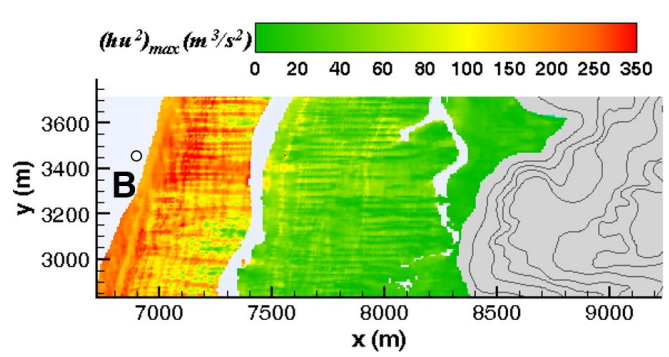

Fig. 12 Spatial variation of $h_{\max }$ and $\left(h u^{2}\right)_{\max }$ : (a) $h_{\max }$ over the whole domain; (b) $h_{\max }$ in central Seaside; (c) $\left(h u^{2}\right)_{\max }$ over the whole domain; (d) $\left(h u^{2}\right)_{\max }$ in central Seaside.

\subsection{Forces and damage assessment}

The predicted maximum unit-width forces on each building are presented in Fig. 13(a). The magnitude of the forces has a clear decreasing trend from the coast to the inland in general. A zoom-in image is shown in Fig. 13(b), in which the large U-shape building near to the shoreline and the L-shape building close to east bank of the first river are outlined with black solid lines. These large buildings may occupy multiple tax lots and therefore contain multiple data points of the maximum unit-width forces. Certain individual points may have colours different from other points in the same building, indicating different forces. The discrepancy may come from the single-building assumption for each tax lot, based on which a large building may be split into multiple buildings.

(a)

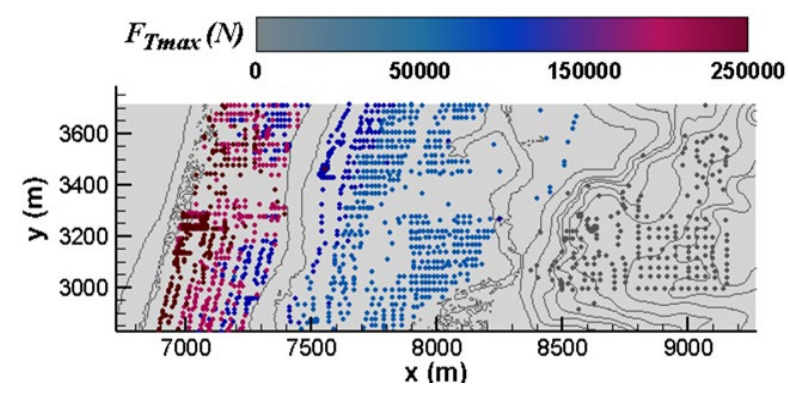

(b)

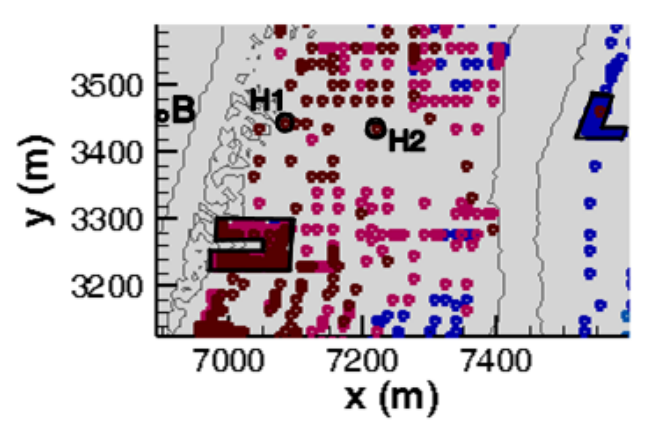

Fig. 13 Spatial distribution of the calculated maximum unit-width forces: (a) the whole central area of Seaside; (b) zoom-in image showing example large buildings. 
In Fig. 13(b) two individual buildings marked respectively as $\mathrm{H} 1$ and $\mathrm{H} 2$ are used as examples to demonstrate the simulation results. The relevant building information and predicted maximum unit-width forces on $\mathrm{H} 1$ and $\mathrm{H} 2$ are listed in Table 4. Table 5 presents the corresponding design capacity, yield capacity, ultimate capacity and the final damage state of the two buildings predicted by the current building damage assessment framework.

Table 4: Relevant building information and predicted maximum unit-width forces for buildings $\mathrm{H} 1$ and $\mathrm{H} 2$.

\begin{tabular}{|c|c|c|c|c|c|c|c|}
\hline Building & $\mathrm{x}(\mathrm{m})$ & $\mathrm{y}(\mathrm{m})$ & $\begin{array}{c}\text { Building } \\
\text { Type }\end{array}$ & Floor & Design Level & $\begin{array}{c}\text { Tax Lot } \\
\text { Area }\left(\mathrm{m}^{2}\right)\end{array}$ & $\begin{array}{c}\text { Maximum } \\
\text { force }(\mathrm{N} / \mathrm{m})\end{array}$ \\
\hline $\mathrm{H} 1$ & 7084 & 3443 & W2 & 2 & Moderate & 4645 & 326671.99 \\
\hline H2 & 7220 & 3436 & C1 & 6 & High & 907 & 275619.41 \\
\hline
\end{tabular}

Table 5: The design capacity, yield capacity, ultimate capacity and the final damage state of $\mathrm{H} 1$ and $\mathrm{H} 2$.

\begin{tabular}{|c|c|c|c|c|}
\hline Building & $\begin{array}{c}\text { Design Capacity, } \\
C_{S} W_{\mathrm{i}}(\mathrm{N})\end{array}$ & $\begin{array}{c}\text { Yield Capacity, } \\
\gamma C_{S} W_{\mathrm{i}}(\mathrm{N})\end{array}$ & $\begin{array}{c}\text { Ultimate Capacity, } \\
\lambda \gamma C_{S} W_{\mathrm{i}}(\mathrm{N})\end{array}$ & Damage State \\
\hline $\mathrm{H} 1$ & 4170861.63 & 6256292.44 & 15640731.09 & Complete \\
\hline $\mathrm{H} 2$ & 3612327.04 & 4515408.8 & 13546226.4 & Slight \\
\hline
\end{tabular}

The damage assessment result caused by the 1000-year tsunami event is presented in Fig. 14(a) for the whole central Seaside area, in which the five damage levels are marked in different colours. Fig. 14 (b) provides a zoom-in plot to display the damage states of some example buildings including $\mathrm{H} 1$ and $\mathrm{H} 2$. It is evident that, from the shoreline to inland, the tsunami impact on buildings (i.e. building damage) decreases. In the area between the shoreline and the first river, most buildings are predicted to be 'Complete Damage'. However, it is noticed that the U-shape building near to the shoreline is marked by green dots, indicating 'Slight Damage'. This is a commercial RC structure built with High-Code, and can hence withstand higher tsunami impact compared with the surrounding buildings. All of the timber buildings distributed on the upper-right (north-east) side of the first river are in 'Extensive Damage' state. The building types are mixed on the lower-right (south-east) side of the first river, and the damage state levels subsequently range from 'Extensive Damage' to 'Slight Damage' in this area. The buildings behind the east bank of the second river are mostly in 'No Damage' level, consistent with water elevation prediction shown in Fig. 12. 


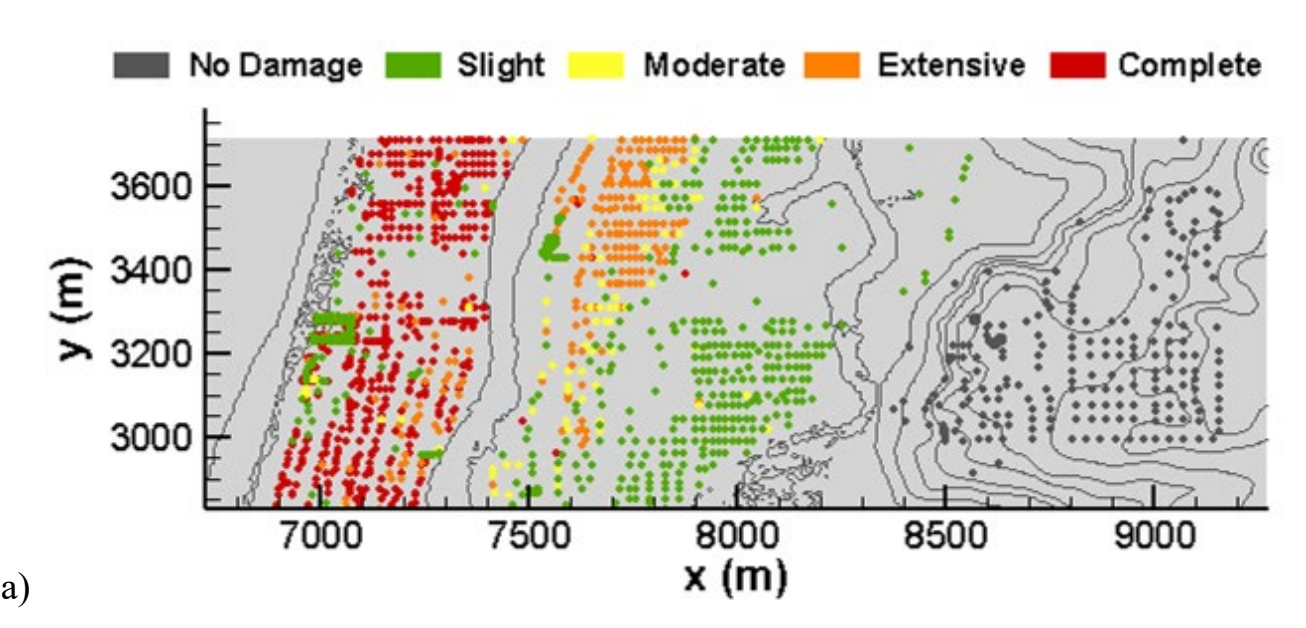

(a)

(b)

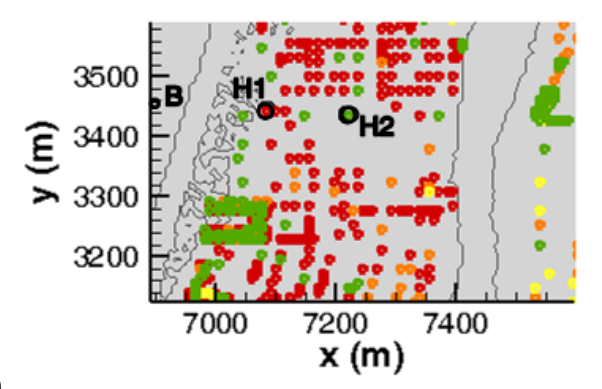

Fig. 14 Predicted building damage states: (a) the whole central Seaside area; (b) zoom-in plot displaying the damage states for the example buildings.

Park et al. (2017) investigated the probability of 'complete damage' of buildings in this area when facing an identical tsunami event (simulated with different models), using tsunami fragility curves based on two IMs, $h_{\max }$ (S2013 model) and $\left(h u^{2}\right)_{\max }$ (FEMA model). The damage assessment results obtained from the current model compare well and are generally consistent with those reported by Park et al. (2017). The buildings with $80 \%$ or higher probability of 'complete damage' as classified by Park et al. (2017) are mostly predicted as 'Complete Damage' by the current model in Fig. 14. The buildings with a probability of $60 \%$ or less of 'complete damage' in Park et al. (2017) are more likely classified as 'Extensive Damage', 'Moderate Damage' and 'Slight Damage' in the current study. Particularly for the buildings off the right (east) bank of the first river, most of them are classified as 'Moderate Damage' by the current model rather than 'complete damage' with a probability of 0 to $20 \%$ in Park et al. (2017). As a summary, although the assessment methods and the definition of damage states are different, the two independent sets of results are generally consistent.

\subsection{Sensitivity tests}

When assessing building damage using the current approach, the parameters associated with the buildings and the force calculation may influence and subsequently introduce uncertainties to the final results of estimating damage states. As detailed in the equations presented in Section 2 , the values of most of the model parameters are either fixed or directly calculated. The only parameters that need estimated values are the building area, building width and the Manning coefficient in the hydrodynamic model. The building areas can be accurately estimated with the 
availability of high-quality building data and therefore no further sensitivity analysis will be performed. Following, the sensitivity of model results to the building width and the Manning coefficient are further investigated and discussed.

\subsubsection{Sensitivity to the building width}

Under the same hydrodynamic conditions, the width of the building facing the flow direction (building width, $B$, in Eq. (8)) determines the magnitude of the total tsunami force. In order to validate and confirm the previously mentioned assumption of square buildings adopted in this work, the damage states of the buildings are also predicted using different building width. From the satellite image of central Seaside, most of buildings are rectangular in shape and the length-width ratio ranges from 1:1 to nearly 4:1. For a building with a 4:1 length-width ratio, the worst scenario occurs when the long side directly faces the tsunami wave. In such a case, the building width should be $4 \mathrm{x}$, which is 2 times of the building width obtained based on the square building assumption. In order to evaluate the sensitivity of the results to the building width, tsunami damage to the buildings is reassessed using 1.5 and 2 times of the original building width $B$ (i.e. the width of a building under the square building assumption). The resulting building damage states are presented in Fig. 15(a) and (b) for building width equal to $1.5 B$ and $2 B$, respectively. Clearly, the damage states of most of the buildings near the shoreline, mostly marked as 'Complete Damage' in Fig. 14, remain unchanged. Due to the use of larger building widths, some of the buildings may suffer a higher damage level. For example, the damage states of a few buildings at the upper-right (north-east) side of the first river have changed into 'Complete Damage', and certain buildings at the lower-left (south-west) side of the second river have changed from 'Slight Damage' to 'Moderate Damage' in Fig. 15(b). However, the damage states of most of the buildings in the study area stay the same. Table 6 quantitatively compares the building damage assessment results obtained using different building widths for the three types of buildings in the study site. In the table, 'Num.' denotes the number of buildings associated with a specific type of damage states, '\%' provides the percentage of these buildings calculated against the total number of the building of the same type and ' $\Delta(\%)$ ' is the difference between the percentages (with the percentage obtained using building width $B$ as a reference). After increasing the building widths, the damage states of some buildings have changed from 'Slight Damage' or 'Moderate Damage' to more serious states, particularly for timber buildings. However, it appears that the change of the damage states is within an acceptable range and mostly less than $10 \%$. 
(a)

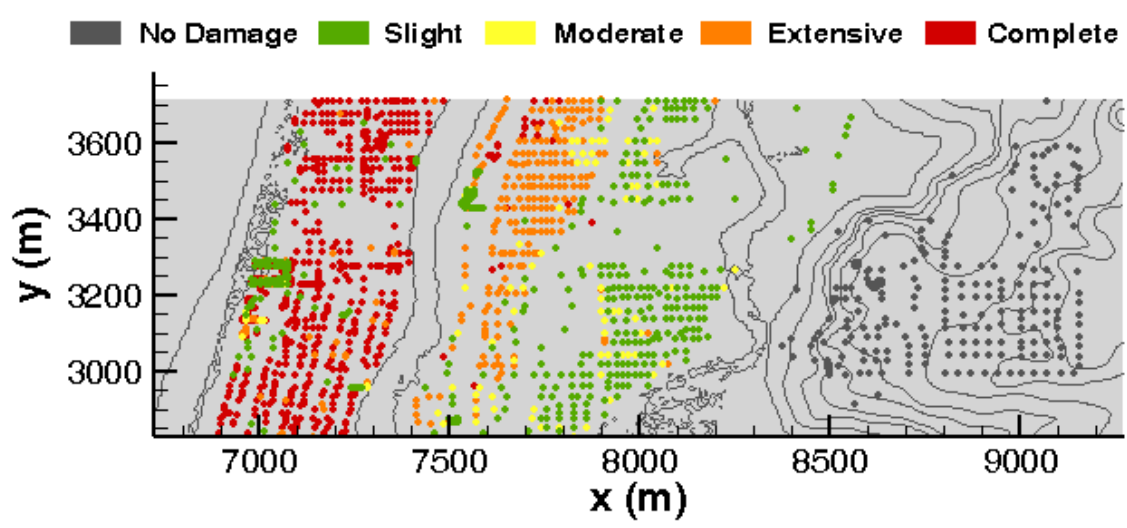

No Damage $\square$ Slight $\quad$ Moderate $\square$ Extensive Complete

(b)

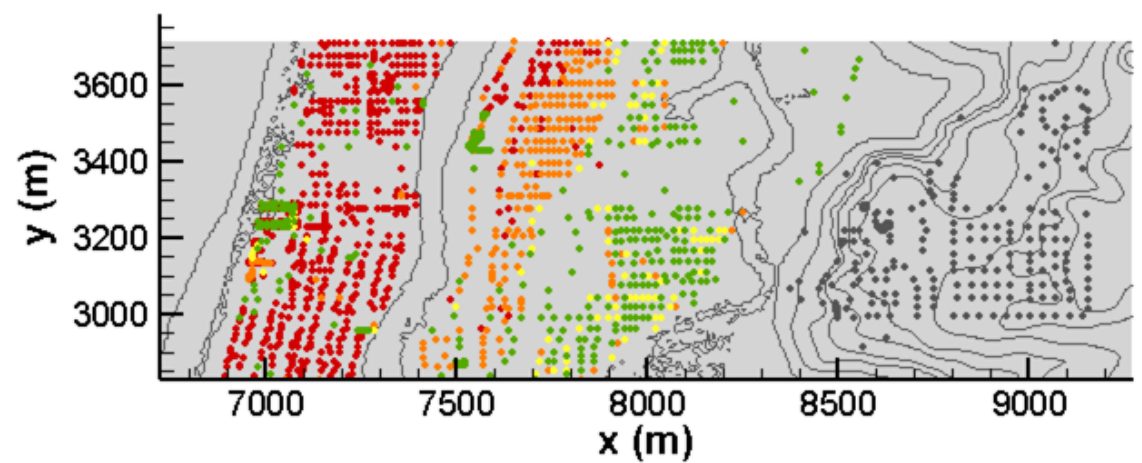

Fig. 15 Building damage states assessed using different building widths: (a) $1.5 B$; (b) $2 B$.

As a summary, a building will receive a higher total force when a longer side faces the incident tsunami wave. But due to the linear relationship, the total force received by the entire building and hence its damage state are not expected to be highly sensitive to the choice of building width. It is also worth mentioning that buildings are also assumed to face the tsunami wave directly (i.e. perpendicular to the flow direction) in the current assessment. When there is an angle between the building width and the flow direction, the projected width should be used, which is obviously less than the adopted building width. Therefore, the current simulation results may be conservative, which may not be a bad thing for engineering design.

Table 6: Quantitative comparison of the building damage assessment results obtained using different building widths.

\begin{tabular}{|c|c|c|c|c|c|c|c|c|c|}
\hline \multirow{2}{*}{$\begin{array}{l}\text { Building } \\
\text { Type }\end{array}$} & \multirow{2}{*}{$\begin{array}{l}\text { Damage } \\
\text { State }\end{array}$} & \multicolumn{2}{|l|}{$1 B$} & \multicolumn{3}{|l|}{$1.5 B$} & \multicolumn{3}{|l|}{$2 B$} \\
\hline & & Num. & $\%$ & Num. & $\%$ & $\Delta(\%)$ & Num. & $\%$ & $\Delta(\%)$ \\
\hline \multirow[t]{5}{*}{ W1 } & Complete & 242 & 32.27 & 267 & 35.6 & 3.33 & 307 & 40.93 & 8.66 \\
\hline & Extensive & 134 & 17.87 & 135 & 18 & 0.13 & 123 & 16.4 & -1.47 \\
\hline & Moderate & 26 & 3.46 & 48 & 6.4 & 2.94 & 54 & 7.2 & 3.74 \\
\hline & Slight & 313 & 28.4 & 165 & 22 & -6.4 & 131 & 17.47 & -10.93 \\
\hline & No Damage & 135 & 18 & 135 & 18 & 0 & 135 & 18 & 0 \\
\hline \multirow[t]{2}{*}{ W2 } & Complete & 75 & 30.99 & 89 & 36.78 & 5.79 & 99 & 40.91 & 9.92 \\
\hline & Extensive & 33 & 13.64 & 35 & 14.46 & 0.82 & 35 & 14.46 & 0.82 \\
\hline
\end{tabular}




\begin{tabular}{|l|l|l|l|l|l|l|l|l|l|}
\hline \multirow{5}{*}{} & Moderate & 16 & 6.61 & 12 & 4.96 & -1.65 & 6 & 2.48 & -4.13 \\
\cline { 2 - 10 } & Slight & 66 & 27.27 & 54 & 22.31 & -4.96 & 50 & 20.66 & -6.61 \\
\cline { 2 - 10 } & No Damage & 52 & 21.49 & 52 & 21.49 & 0 & 52 & 21.49 & 0 \\
\hline C1 & Complete & 123 & 28.87 & 140 & 32.86 & 3.99 & 152 & 35.68 & 6.81 \\
\cline { 2 - 10 } & Extensive & 48 & 11.27 & 73 & 17.13 & 5.86 & 81 & 19.01 & 7.74 \\
\cline { 2 - 10 } & Moderate & 42 & 9.86 & 25 & 5.87 & -3.99 & 20 & 4.70 & -5.16 \\
\cline { 2 - 10 } & Slight & 186 & 43.66 & 161 & 37.80 & -5.86 & 146 & 34.27 & -9.39 \\
\cline { 2 - 10 } & No Damage & 27 & 6.34 & 27 & 6.34 & 0 & 27 & 6.34 & 0 \\
\hline
\end{tabular}

4.4.2 Sensitivity to the Manning coefficient

The value of Manning coefficient influences the flow hydrodynamics through bed friction stresses and is the only parameter that needs to be determined in the hydrodynamic tsunami model. The sensitivity of the shallow flow hydrodynamics to the Manning coefficient has been intensively investigated and analysed in the context of flood modelling [e.g. (Liang and Smith, 2015)]. The complex landscape, land-use and built patterns in a real-world computational domain pose a great challenge in specifying appropriate Manning coefficient to facilitate large-scale shallow flow simulations, especially in urban areas as considered in the current study. In order to better understand the sensitivity of the simulation results, i.e. building damage herein, to the choice of Manning coefficient, two extra values of the Manning coefficient are selected within the normal range for urban ground surface ( $n=0.02$ and $n=0.04$ ) (Koshimura et al., 2009) to perform further simulations.

(a)
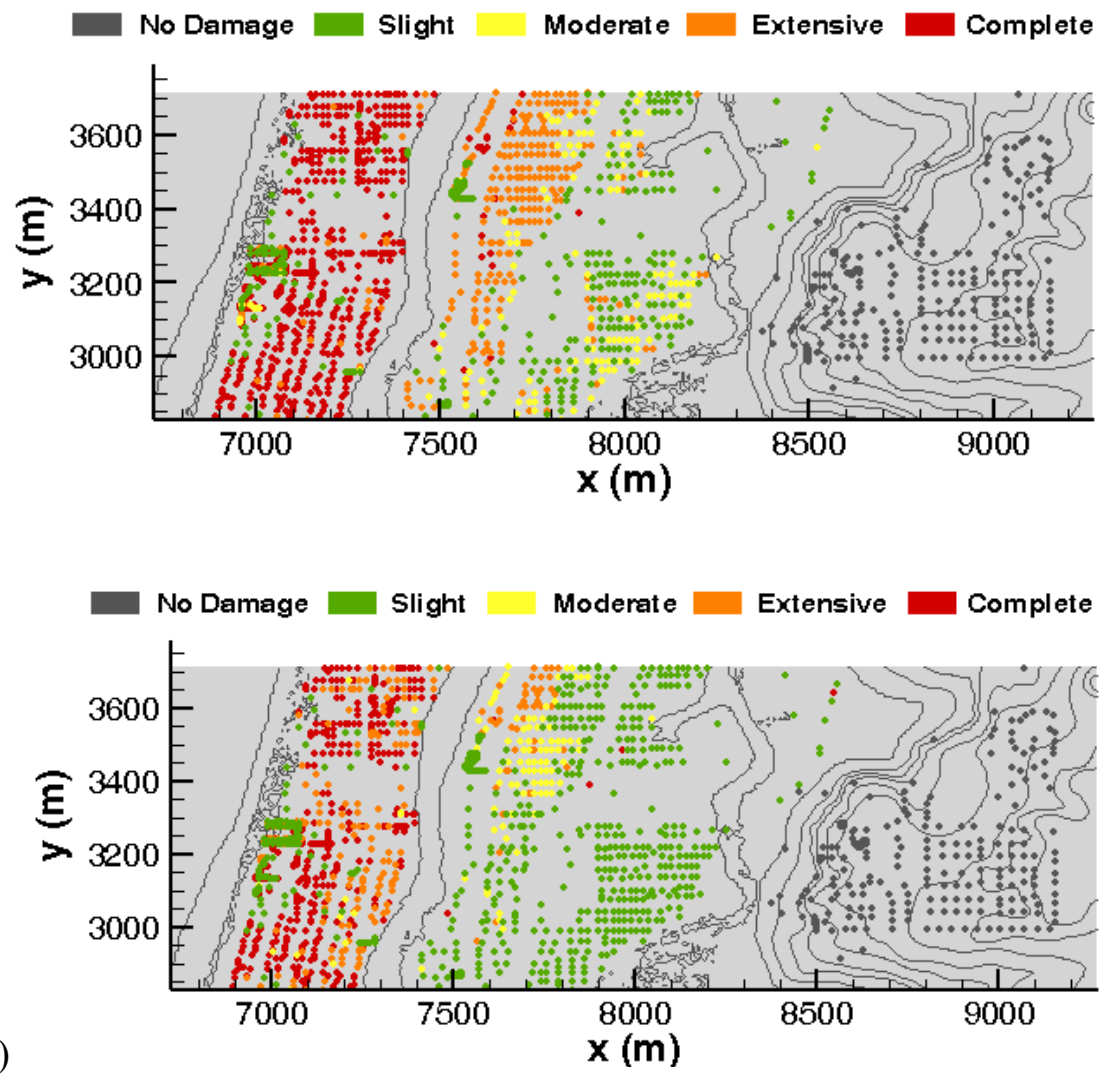
Fig. 16 Building damage simulated with different Manning coefficients: (a) $n=0.02$; (b) $n=$ 0.04 .

Fig. 16 presents the building damage states simulated with $n=0.02$ and $n=0.04$, respectively. Bigger Manning coefficient translates into larger bed friction and subsequently smaller flow velocity due to more intense energy dissipation. As a result, the building damage states predicted with $n=0.02$, as presented in the Fig. 16(a), have become worsened compared with the results obtained with $n=0.03$ (Fig. 14); on the other hand, the damage states estimated with $n=0.04$, as shown in the Fig. 16(b), have turned out to be safer as expected. Table 7 shows the quantitative comparison of the results obtained using different Manning coefficients for the three different types of buildings in Seaside. The notations adopted are identical to those used previously in Table 6. Generally, with different Manning coefficients, the simulated results of building damage have undergone small changes accordingly. The results are generally not so sensitive to the variation of the Manning coefficient in the region between the shoreline and the first river, and the damage states of most buildings remain unchanged. The results appear to be relatively more sensitive for those buildings located between the two rivers, and the damage states of certain buildings have changed one level up or down depending the values of Manning coefficient. As a whole, for those buildings with modified damage states, most of them are timber buildings and the damage states of most RC buildings remain unchanged. The results indicate that light-weight buildings (e.g. timber buildings) are more sensitive to the variation of Manning coefficient, and hence the change of tsunami forces.

Table 7: Quantitative comparison of the building damage assessment results obtained using different Manning coefficients.

\begin{tabular}{|c|c|c|c|c|c|c|c|c|c|}
\hline \multirow{2}{*}{$\begin{array}{l}\text { Building } \\
\text { Type }\end{array}$} & \multirow{2}{*}{$\begin{array}{l}\text { Damage } \\
\text { State }\end{array}$} & \multicolumn{2}{|c|}{$n=0.03$} & \multicolumn{3}{|c|}{$n=0.02$} & \multicolumn{3}{|c|}{$n=0.04$} \\
\hline & & Num. & $\%$ & Num. & $\%$ & $\Delta(\%)$ & Num. & $\%$ & $\Delta(\%)$ \\
\hline \multirow[t]{5}{*}{ W1 } & Complete & 242 & 32.27 & 267 & 35.6 & 3.33 & 194 & 25.87 & -6.4 \\
\hline & Extensive & 134 & 17.87 & 151 & 20.13 & 2.26 & 103 & 13.73 & -4.14 \\
\hline & Moderate & 26 & 3.46 & 84 & 11.2 & 7.74 & 64 & 8.53 & 5.07 \\
\hline & Slight & 313 & 28.4 & 113 & 15.07 & -13.33 & 254 & 33.87 & 5.47 \\
\hline & No Damage & 135 & 18 & 135 & 18 & 0 & 135 & 18 & 0 \\
\hline \multirow[t]{5}{*}{ W2 } & Complete & 75 & 30.99 & 88 & 36.36 & 5.37 & 58 & 23.97 & -7.02 \\
\hline & Extensive & 33 & 13.64 & 39 & 16.12 & 2.48 & 30 & 12.4 & -1.24 \\
\hline & Moderate & 16 & 6.61 & 15 & 6.20 & -0.41 & 17 & 7.02 & 0.41 \\
\hline & Slight & 66 & 27.27 & 48 & 19.83 & -7.44 & 85 & 35.12 & 7.85 \\
\hline & No Damage & 52 & 21.49 & 52 & 21.49 & 0 & 52 & 21.49 & 0 \\
\hline \multirow[t]{5}{*}{$\mathrm{C} 1$} & Complete & 123 & 28.87 & 140 & 32.86 & 3.99 & 94 & 22.07 & -6.8 \\
\hline & Extensive & 48 & 11.27 & 71 & 16.67 & 5.4 & 75 & 17.6 & 6.33 \\
\hline & Moderate & 42 & 9.86 & 27 & 6.34 & -3.5 & 17 & 3.99 & -5.87 \\
\hline & Slight & 186 & 43.66 & 161 & 37.79 & -5.87 & 213 & 50 & 6.34 \\
\hline & No Damage & 27 & 6.34 & 27 & 6.34 & 0 & 27 & 6.34 & 0 \\
\hline
\end{tabular}




\section{Conclusions}

This work proposes a new deterministic approach for assessing tsunami-induced building damage at a city scale. The new building damage assessment framework is based on a finite volume Godunov-type hydrodynamic numerical model for predicting tsunami hydrodynamics and the resulting impact forces. The estimated tsunami forces and the building damage states are directly and explicitly linked through mechanical analysis and building capacity curves of lateral force resisting systems, with the capacity coefficients and damage states obtained from the widely used seismic assessment model HAZUS-MH.

After being successfully validated for accurate prediction of tsunami hydrodynamics and forces, the overall framework is applied to simulate the inundation and assess the building damage caused by a hypothetic 1000-year tsunami event in the City of Seaside, Oregon, United States. The simulation results in terms of spatial distribution of the maximum water depth $h_{\max }$ and maximum flow momentum $\left(h u^{2}\right)_{\max }$ agree well with those obtained by Park et al. (2017) using different models. The building damage states predicted by the current deterministic approach are also consistent with those presented by Park et al. (2017) using probability-based approaches. Further simulations are conducted to analyze the sensitivity of the building damage results to the two key model parameters, i.e. building width and Manning coefficient. Generally, the building damage states are predicted to be not very sensitive to the choice of these parameters. The damage states predicted by different values of the parameters may change slightly for certain timber buildings, but mostly remain unchanged for RC buildings.

Compared with the widely used probability-based approaches, the current framework directly estimates building damage by quantifying the forces acting on buildings, automatically taken into the complex wave-structure interaction and wave transformation around buildings using a high-performance hydrodynamic model solving the 2D shallow water equations. Therefore the proposed building damage assessment framework provides a more generalized approach applicable to different cases. Furthermore, the computationally demanding component of the framework, i.e. the hydrodynamic tsunami model, is implemented on GPUs to achieve high-performance computing. The framework is therefore most suitable for wider applications over a large domain involving millions of computational nodes, providing a useful tool for urban planning and building design in tsunami-prone areas.

Currently, the model only considers building damage caused by hydrostatic and hydrodynamic forces in the horizontal direction. However, the interaction between tsunami waves and buildings and hence the forcing process are much more complicated in reality, and other relevant forces, e.g. buoyancy and debris impact, may be further considered and incorporated in the building damage assessment framework in the future.

\section{Acknowledgement}


This work is supported by the China Scholarships Council (No. 201606710054), the National Natural Science Foundation of China (NSFC) through a standard research award (Ref. 51379074), and the State Major Project of Water Pollution Control and Management (2017ZX07603-001).

\section{References}

Amouzgar, R., Liang, Q., Clarke, P.J., Yasuda, T. and Mase, H., 2016. Computationally efficient tsunami modeling on graphics processing units (gpus). International Journal of Offshore and Polar Engineering, 26(02): 154-160.

Arimitsu, T. and Kawasaki, K., 2016. Development of estimation method of tsunami wave pressure exerting on land structure using depth-integrated flow model. Coastal Engineering Journal: 1640021.

Attary, N., Unnikrishnan, V.U., van de Lindt, J.W., Cox, D.T. and Barbosa, A.R., 2017. Performance-based tsunami engineering methodology for risk assessment of structures. Engineering Structures, 141: 676-686.

Attary, N., van de Lindt, J.W., Unnikrishnan, V.U., Barbosa, A.R. and Cox, D.T., 2016. Methodology for development of physics-based tsunami fragilities. Journal of Structural Engineering, 143(5): 04016223.

Bernard, E. et al., 2010. Tsunami resilient communities. Proceedings of the OceanObs09: Sustained Ocean Observations and Information for Society Conference, p.^pp. 4.

Borzi, B., Rui, P. and Crowley, H., 2008. Simplified pushover-based vulnerability analysis for large-scale assessment of rc buildings. Engineering Structures, 30(3): 804-820.

Bricker, J.D. and Nakayama, A., 2014. Contribution of trapped air, deck superelevation, and nearby structures to bridge deck failure during a tsunami. Journal of Hydraulic Engineering, 140(5): 05014002.

Brodtkorb, A.R., 2010. Scientific computing on heterogeneous architectures. PhD, University of Oslo.

Chanson, H., 2006. Tsunami surges on dry coastal plains: Application of dam break wave equations. Coastal Engineering Journal, 48(04): 355-370.

Chock, G., Carden, L., Robertson, I., Olsen, M. and Yu, G., 2013. Tohoku tsunami-induced building failure analysis with implications for us tsunami and seismic design codes. Earthquake spectra, 29(s1): S99-S126.

Chow, V.T., 1959. Open channel hydraulics.

Dall'Osso, F. and Dominey-Howes, D., 2013. Coastal vulnerability to multiple inundation sources-covermar project-literature review. Report Prepared for the Sydney Coastal Councils Group Inc.: 87.

Dall'Osso, F., Gonella, M., Gabbianelli, G., Withycombe, G. and Dominey-Howes, D., 2009. A revised (ptva) model for assessing the vulnerability of buildings to tsunami damage. Natural Hazards and Earth System Sciences, 9(5): 1557-1565.

Dias, W., Yapa, H. and Peiris, L., 2009. Tsunami vulnerability functions from field surveys and monte carlo simulation. Civil Engineering and Environmental Systems, 26(2): 181-194. 
FEMA, 2011. Multi-hazard loss estimation methodology earthquake model: Earthquake model, hazus-mh mr4 technical mannual. National Institute of Building Sciences (NIBS), Washington, D.C.

FEMA, 2012. Guidelines for design of structures for vertical evacuation from tsunamis., FEMA P646, 2nd Ed., Washington, DC.

Ghobarah, A., 2001. Performance-based design in earthquake engineering: State of development. Engineering structures, 23(8): 878-884.

Gulati, B., 2006. Earthquake risk assessment of buildings: Applicability of hazus in dehradun, india, ITC.

Hatzikyriakou, A. and Lin, N., 2017. Impact of performance interdependencies on structural vulnerability: A systems perspective of storm surge risk to coastal residential communities. Reliability Engineering \& System Safety, 158: 106-116.

Hayashi, K., Tamura, S., Nakashima, M., Chung, Y. and Hoki, K., 2012. Evaluation of tsunami load and building damage mechanism observation in the 2011 off pacific coast of tohoku earthquake. 15th World Conference on Earthquake Engineering, Paper ID, p.^pp.

Headquarters, E.D.C., 2016. Damage situation and police countermeasures associated with 2011 tohoku district-off the pacific ocean earthquake. Tokyo: National Police Agency of Japan.

Howard, B. et al., 2012. Spatial distribution of urban building energy consumption by end use. Energy \& Buildings, 45: 141-151.

Kiefer, J.C. and Willett, J.S., 1996. Analysis of nonresidential content value and depth-damage data for flood damage reduction studies, DTIC Document.

Kircher, C.A., Whitman, R.V. and Holmes, W.T., 2006. Hazus earthquake loss estimation methods. Natural Hazards Review, 7(2): 45-59.

Koshimura, S., Oie, T., Yanagisawa, H. and Imamura, F., 2009. Developing fragility functions for tsunami damage estimation using numerical model and post-tsunami data from banda aceh, indonesia. Coastal Engineering Journal, 51(03): 243-273.

Leelawat, N., Suppasri, A., Murao, O. and Imamura, F., 2016. A study on the influential factors on building damage in sri lanka during the 2004 indian ocean tsunami. Journal of Earthquake and Tsunami: 1640001.

Liang, Q., 2010. Flood simulation using a well-balanced shallow flow model. Journal of Hydraulic Engineering, 136(9): 669-675.

Liang, Q. and Borthwick, A.G., 2009. Adaptive quadtree simulation of shallow flows with wet-dry fronts over complex topography. Computers \& Fluids, 38(2): 221-234.

Liang, Q. et al., 2016. Hydrodynamic modelling of flow impact on structures under extreme flow conditions. Journal of Hydrodynamics, Ser. B, 28(2): 267-274.

Liang, Q. and Smith, L.S., 2015. A high-performance integrated hydrodynamic modelling system for urban flood simulations. Journal of Hydroinformatics, 17(4): 518.

Lynett, P.J., 2016. Precise prediction of coastal and overland flow dynamics: A grand challenge or a fool's errand. Journal of Disaster Research Vol, 11(4): 1.

Mas, E. et al., 2012. Developing tsunami fragility curves using remote sensing and survey data of the 2010 chilean tsunami in dichato. Natural Hazards and Earth System Sciences, 12(8): 2689-2697. 
McDonnell, S., Madar, J. and Been, V., 2011. Minimum parking requirements and housing affordability in new york city. Housing Policy Debate, 21(1): 45-68.

Mori, N., Yoneyama, N. and Pringle, W., 2015. Effects of the offshore barrier against the 2011 off the pacific coast of tohoku earthquake tsunami and lessons learned, Post-tsunami hazard. Springer, pp. 121-132.

Murao, O., 2010. Vulnerability functions for buildings based on damage survey data in sri lanka after the 2004 indian ocean tsunami. 75(651): 1021-1027.

Neighbors, C.J., Cochran, E.S., Caras, Y. and Noriega, G.R., 2013. Sensitivity analysis of fema hazus earthquake model: Case study from king county, washington. Natural Hazards Review, 14(2): 134-146.

NGDC/WDS, 2016. Ngdc/wds global historical tsunami database.

Nistor, I., Palermo, D., Cornett, A. and Al-Faesly, T., 2011. Experimental and numerical modeling of tsunami loading on structures. Coastal Engineering Proceedings, 1(32): 2.

Nouri, Y., Nistor, I., Palermo, D. and Cornett, A., 2010. Experimental investigation of tsunami impact on free standing structures. Coastal Engineering Journal, 52(01): 43-70.

Papathoma, M. and Dominey-Howes, D., 2003. Tsunami vulnerability assessment and its implications for coastal hazard analysis and disaster management planning, gulf of corinth, greece. Natural Hazards and Earth System Science, 3(6): 733-747.

Park, H. and Cox, D.T., 2016. Probabilistic assessment of near-field tsunami hazards: Inundation depth, velocity, momentum flux, arrival time, and duration applied to seaside, oregon. Coastal Engineering, 117: 79-96.

Park, H., Cox, D.T. and Barbosa, A.R., 2017. Comparison of inundation depth and momentum flux based fragilities for probabilistic tsunami damage assessment and uncertainty analysis. Coastal Engineering, 122: 10-26.

Park, H., Cox, D.T., Lynett, P.J., Wiebe, D.M. and Shin, S., 2013. Tsunami inundation modeling in constructed environments: A physical and numerical comparison of free-surface elevation, velocity, and momentum flux. Coastal Engineering, 79: 9-21.

Petrone, C., Rossetto, T. and Goda, K., 2017. Fragility assessment of a rc structure under tsunami actions via nonlinear static and dynamic analyses. Engineering Structures, 136: $36-53$.

Ploeger, S.K., Atkinson, G.M. and Samson, C., 2010. Applying the hazus-mh software tool to assess seismic risk in downtown ottawa, canada. Natural Hazards, 53(1): 1-20.

Reese et al., 2011. Empirical building fragilities from observed damage in the 2009 south pacific tsunami. Earth-Science Reviews, 107(1): 156-173.

Reese et al., 2007. Tsunami vulnerability of buildings and people in south java-field observations after the july 2006 java tsunami. Natural Hazards and Earth System Sciences, 7(5): 573-589.

Robertson, I., Paczkowski, K., Riggs, H. and Mohamed, A., 2011. Tsunami bore forces on walls. ASME 2011 30th International Conference on Ocean, Offshore and Arctic Engineering, p.^pp. 395-403.

Rueben, M. et al., 2011. Optical measurements of tsunami inundation through an urban waterfront modeled in a large-scale laboratory basin. Coastal Engineering, 58(3): 229-238.

Santo, J. and Robertson, I.N., 2010. Lateral loading on vertical structural elements due to a tsunami bore. University of Hawaii, Honolulu, Report No. UHM/CEE/10-02. 
Schneider, P.J. and Schauer, B.A., 2006. Hazus-its development and its future. Natural Hazards Review, 7(7): 40-44.

Shafiei, S., Melville, B.W. and Shamseldin, A.Y., 2016. Experimental investigation of tsunami bore impact force and pressure on a square prism. Coastal Engineering, 110: 1-16.

Singhal, A. and Kiremidjian, A.S., 1996. Method for probabilistic evaluation of seismic structural damage. Journal of Structural Engineering, 122(12): 1459-1467.

Smith, L.S. and Liang, Q., 2013. Towards a generalised gpu/cpu shallow-flow modelling tool. Computers \& Fluids, 88: 334-343.

Suppasri, Koshimura, S. and Imamura, F., 2011. Developing tsunami fragility curves based on the satellite remote sensing and the numerical modeling of the 2004 indian ocean tsunami in thailand. Natural Hazards and Earth System Sciences, 11(1): 173-189.

Suppasri et al., 2013. Building damage characteristics based on surveyed data and fragility curves of the 2011 great east japan tsunami. Natural Hazards, 66: 319-341.

Suppasri, A., Kamthonkiat, D., Gokon, H., Matsuoka, M. and Koshimura, S., 2012. Application of remote sensing for tsunami disaster. INTECH Open Access Publisher.

Tarbotton, C., Dall'Osso, F., Dominey-Howes, D. and Goff, J., 2015. The use of empirical vulnerability functions to assess the response of buildings to tsunami impact: Comparative review and summary of best practice. Earth-Science Reviews, 142: 120-134.

Tokimatsu, K., Ishida, M. and Inoue, S., 2016. Tsunami-induced overturning of buildings in onagawa during the 2011 tohoku earthquake. Earthquake Spectra, 32(4): 1989-2007.

Toro, E.F., 2001. Shock-capturing methods for free-surface shallow flows.

Villaverde, R., 2007. Methods to assess the seismic collapse capacity of building structures: State of the art. Journal of Structural Engineering, 133(1): 57-66.

Wei, Z. and Jia, Y., 2014. Non-hydrostatic finite element model for coastal wave processes. Coastal Engineering, 92: 31-47.

Wiebe, D.M. and Cox, D.T., 2014. Application of fragility curves to estimate building damage and economic loss at a community scale: A case study of seaside, oregon. Natural hazards, 71(3): 2043-2061.

Xiong, Y. et al., 2016. High-performance simulation of tsunami inundation and impact on building structures. The 26th International Ocean and Polar Engineering Conference, $p . \wedge p p$.

$\mathrm{Xu}, \mathrm{G}$. and Cai, C., 2015. Numerical simulations of lateral restraining stiffness effect on bridge deck-wave interaction under solitary waves. Engineering Structures, 101: 337-351.

Yeh, H., Barbosa, A.R., Ko, H. and Cawley, J.G., 2014. Tsunami loadings on structures: Review and analysis. Coastal Engineering Proceedings, 1(34): 4.

Yeh, H., Sato, S. and Tajima, Y., 2013. The 11 march 2011 east japan earthquake and tsunami: Tsunami effects on coastal infrastructure and buildings. Pure and Applied Geophysics, 170(6-8): 1019-1031.

Zhao, Z. and He, J., 2010. Hydraulics. Tsinghua University Press, China. 